\title{
Transient simulation of finned heat sinks embedded with PCM for electronics cooling
}

Adeel Arshad $^{\mathrm{a}}$, Mark Jabbal ${ }^{\mathrm{a}}$, Pouyan Talebizadeh Sardaria ${ }^{\mathrm{a}}$, Muhammad Anser Bashir $^{\mathrm{b}}$, Hamza Farajic ${ }^{c}$ Yuying Yan ${ }^{\mathrm{a}, \mathrm{d}, *}$

${ }^{a}$ Fluids 8 Thermal Engineering (FLUTE) Research Group, Faculty of Engineering, University of Nottingham, Nottingham NGr 2RD, UK

${ }^{b}$ Department of Mechanical Engineering, Mirpur University of Science 8 Technology (MUST), Mirpur 10250, AJK, Pakistan

${ }^{c}$ Physics Department, LPMMAT Laboratory, Faculty of Sciences Ain Chock, Hassan II University, Casablanca, Morocco

${ }^{d}$ Research Centre for Fluids and Thermal Engineering, University of Nottingham Ningbo China, Ningbo 315100, China

\begin{abstract}
This paper reports the two-dimensional $(2 D)$ transient numerical simulation of a phase change material (PCM) based finned heat sink to investigate the heat transfer performance for passive cooling of electronic devices. The finned heat sinks of $2 \mathrm{~mm}$ and $3 \mathrm{~mm}$ fin thickness are employed with a constant fin volume fraction of $9 \%$, acting as thermal conductivity enhancer (TCE). The n-eicosane is employed as a PCM inside the heat sink to store the heat generated from the electronic device applied at the heat sink base. Transient numerical simulations are performed using finite--volume-method and conjugate heat transfer and melting/solidification phenomenon are investigated by applying various power levels. The numerical results show that the employed PCM with low temperature keeps the heat sink base temperature in lower limits and uniform melting is observed inside the finned heat sink. With the increase of heating power level, the PCM melting time is decreased for fin thickness heat sinks. By increasing the power level from 4 to $6 \mathrm{~W}$, for the case of $3 \mathrm{~mm}$ fin thickness, the melting time increases by $6.63 \%, 3.59 \%$ and $1.90 \%$ by $3 \mathrm{~mm}$ fin thickness heat sink, compared to the $2 \mathrm{~mm}$ fin thickness heat sink. The developed equations of liquid fraction and modified Nusselt number are obtained as function of modified Fourier number, Stefan number, and Rayleigh number which provide guidelines for generalizing the performance of PCM based finned heat sinks.
\end{abstract}

Keywords: Passive cooling, Finned heat sink, Phase change material, Thermal conductivity enhancer, N-eicosane

\footnotetext{
* Correspondence authors

Email address: yuying.yan@nottingham.ac.uk (Yuying Yan)
} 
Nomenclature

\begin{tabular}{|c|c|c|c|}
\hline$A_{m}$ & Mushy zone & $t_{p}$ & Thickness of PCM between two consecutive fins \\
\hline CFD & Computational fluid dynamics & $u$ & Velocity components in $x$ direction \\
\hline$c_{p}$ & Specific heat (J/kg.K) & $V_{T C E}$ & Volume of TCEs \\
\hline FVM & Finite volume method & $V_{H S}$ & Volume of heat sink \\
\hline Fo & Fourier number & $v$ & Velocity components in $y$ direction \\
\hline$F O^{*}$ & Modified Fourier number & W & Width of heat sink \\
\hline$g$ & Gravity $\left(\mathrm{m} / \mathrm{s}^{2}\right)$ & $2 D$ & Two dimensional \\
\hline$H$ & Total enthalpy $(\mathrm{J} / \mathrm{kg})$ & $T$ & Difference temperature $(\mathrm{K})$ \\
\hline$h$ & Sensible enthalpy $(\mathrm{J} / \mathrm{kg})$ & $H$ & Latent heat $(\mathrm{J} / \mathrm{kg})$ \\
\hline$h_{\text {ref }}$ & Reference enthalpy $(\mathrm{J} / \mathrm{kg})$ & \multicolumn{2}{|c|}{ Greek symbols } \\
\hline$H$ & Height of heat sink & $\beta$ & Thermal expansion coefficient (1/K) \\
\hline$h_{f}$ & Height of fin & $\rho c_{p}$ & Thermal capacitance $\left(\mathrm{J} / \mathrm{m}^{3} \mathrm{~K}\right)$ \\
\hline$k$ & Thermal conductivity (W/m.K) & $\alpha$ & Thermal diffusivity $\left(\mathrm{m}^{2} / \mathrm{s}\right)$ \\
\hline LHSU & Latent heat storage unit & $\mu$ & Dynamic viscosity (Pa.s) \\
\hline$L$ & Latent heat of fusion $(\mathrm{J} / \mathrm{kg})$ & $\rho$ & Density $\left(\mathrm{kg} / \mathrm{m}^{3}\right)$ \\
\hline$N u^{*}$ & Modified Nusselt number & $\rho_{\text {ref }}$ & Reference density $\left(\mathrm{kg} / \mathrm{m}^{3}\right)$ \\
\hline $\mathrm{PCM}$ & Phase change material & $\varphi$ & Porosity function \\
\hline$P$ & Pressure $(\mathrm{Pa})$ & $\gamma$ & Volume fraction of TCEs \\
\hline$q$ & Heat flux $\left(\mathrm{W} / \mathrm{m}^{2}\right)$ & $\theta$ & Dimensionless temperature \\
\hline$R a$ & Rayleigh number & $\tau$ & Dimensionless time \\
\hline$R a^{*}$ & Modified Rayleigh number & $f_{l}$ & Liquid fraction \\
\hline SIMPLE & Semi-Implicit Pressure-Linked Equation & & \\
\hline Ste & Stefan number & & \\
\hline Ste & Modified Stefan number & & \\
\hline$S$ & Source term in momentum equation & & \\
\hline$S_{h}$ & Source term in energy equation & & \\
\hline TCE & Thermal conductivity enhancer & & \\
\hline TM & Thermal management & & \\
\hline $\mathrm{T}$ & Temperature $(\mathrm{K})$ & & \\
\hline$T_{m}$ & Melting temperature $(\mathrm{K})$ & & \\
\hline$T_{i n i}$ & Initial temperature $(\mathrm{K})$ & & \\
\hline$T_{s}$ & Solidus Temperature (K) & & \\
\hline$T_{l}$ & Liquidus temperature (K) & & \\
\hline$T_{r e f}$ & Reference temperature $(\mathrm{K})$ & & \\
\hline$t$ & Time (sec) & & \\
\hline$t_{f}$ & Thickness of fin & & \\
\hline
\end{tabular}




\section{Introduction}

The miniaturization and advanced multi-functionality of electronic devices have undergone a great revolution in current era. Both features result in the overheating of electronic components and lead to the unreliable and dramatic increase in operating temperature [1]. Around $55 \%$ of failures in operating electronic devices are due to the increase in device temperature [2]. Therefore, to overcome the overheating phenomenon and efficient temperature distribution, a novel and efficient cooling technology is needed to avoid any type of failures. Many researchers are working on the electronic cooling system by using piezoelectric energy harvesting mechanism specifically in the field of mechanical and aerospace engineering [3, 4, 5]. In recent years, the invention of passive thermal management (TM) of electronics devices using phase change materials (PCMs) and various thermal conductivity enhancers (TCEs) have introduced a new direction in cooling technologies. PCMs are the best competitors for cooling of electronics devices because of high heat storage density and isothermal process during phase transition [6].

Several studies have been reported which introduced the finned heat sinks as a TCE, filled with PCMs which have high specific and latent heat of fusion with small change in volume. A numerical study proposed by Nayak et al. [7] for TM of electronics using porous matrix and finned (plate-type and rod-type) as a TCEs for PCM filled heat sinks. TCEs of 5\%, $10 \%$ and $15 \%$ volume fractions of TCE were selected in the case of finned heat sinks. Authors marked two findings: firstly $10 \%$ had the better thermal performance and secondly rod-type TCE was more significant in terms of convection of melt front of PCM to transfer heat, which in turn lead to lower chip temperature. Shatikan et al. [8] conducted the transient numerical simulation of a PCM-based heat sink at constant heat flux and performed a dimensional analysis. The results were presented with good agreement with melt fraction in terms of Nusselt, Fourier, modified Stefan and Rayleigh numbers. Further, Saha and Dutta [9, 10] proposed the heat transfer correlation of a plate-fin PCM based heat sink of various enclosures and heat fluxes. The authors suggested that a single correlation of $\mathrm{Nu}$ and $\mathrm{Ra}$ numbers is not enough to relate the performance of heat sink with melt fraction. Wang and Yang [11, 12] conducted a three dimensional numerical study for different number of fins (0, 3 and 6 fins) at heating power level of 2, 3 and $4 \mathrm{~W}$. The authors used the n-eicosane as a PCM and found good agreement with experimental results. Ye et al. [13] performed the simulation of a plate-fin heat storage unit and studied the thermal storage/release characteristics of paraffin wax at different wall temperature and presented the 
results in dimensionless variables. Pakrouh et al. [14] performed the numerical optimization of number of fins, height, thickness and base thickness of heat sink using Taguchi method. The results found that the number of fins had the greatest influence, followed by fin thickness and height at low critical temperature while base thickness had the least effect on the operating temperature. Kant et al. [15] studied the thermal performance of five different PCMs namely capric acid, lauric acid, myristic acid, palmitic acid and stearic acid filled in aluminum containers. The results showed that maximum energy was stored by stearic acid and minimum for capric acid with the same boundary conditions. Sahoo et al. [16] conducted the numerical simulation of orthotropic composite fins as the TCEs using n-eicosane as a PCM and reported that orthotropic fins showed better thermal performance in reducing the base temperature compared to isotropic fins. Further, it was suggested that using orthotropic fins instead of isotropic fins minimized the thermal constraints, as well as weight, on the thermal electronic components. Vogel et al. [17] carried out experimental and numerical studies of eutectic mixture of sodium nitrate and potassium nitrate $\left(\mathrm{KNO}_{3}+\mathrm{NaNO}_{3}\right)$ as a PCM on a high temperature flat-plate as TES system in a natural convection mode. A convective enhancement factor was introduced and it was found that natural convection heat transfer enhancement was increased with higher widths and smaller heights of TES system. Joshi and Rathod [18] proposed a numerical study to obtain the best fin size and location in a rectangular enclosure to give the minimum melting time for a given fin-to-PCM volume ratio to increase the thermal transport of the PCM. The authors used four different configurations and found that the fin-to-PCM volume ratio could be decreased by half and could increase the total volume of the thermal energy storage. Further, it was concluded that the reduction in volume of fins at the top portion of the TES system did not change the overall rate of PCM melting significantly. Ji et al. [19] carried out a numerical investigation of a vertically heated rectangular enclosure to suppress the non-uniform heat transfer of PCM melting with fins angled at $0^{\circ},+15^{\circ},+30^{\circ},-15^{\circ}$ and $-30^{\circ}$. It was found that -15 fins increased the PCM melting rate significantly and reduced the melting duration by $62.7 \%$ compared with the same length fins at $0^{\circ}$. Kazemi et al. 20] investigated the arrangement of longitudinal fins from $60^{\circ}$ to $120^{\circ}$ to improve heat transfer by considering the triple-fin heat exchangers. The authors found that the best cases for double-fin (reducing angle from $150^{\circ}$ to $45^{\circ}$ ) and triple-fin (increasing angle from $60^{\circ}$ to $120^{\circ}$ ) resulted in $62 \%$ and $22.5 \%$ reduction in melting time, respectively, compared with the simple heat exchanger. Kalbasi et al. [21] numerically investigated the optimum number of fins of PCM filled heat sink and 
proposed relations for optimum fin number, fin spacing and fin height for various input heat fluxes.

Recently, Arshad and his co-authors [22, 23, 24, 25, 26] conducted parametric experimental studies for square and circular profiles pin-fin heat sinks based on the number of fins, fin thickness and fin configuration filled with six different types of PCM of varying melting temperatures and latent heat of fusion at constant and intermittent heating. The authors selected $9 \%$ volume fraction of TCEs and concluded that $2 \mathrm{~mm}$ and $3 \mathrm{~mm}$ fin thickness of square and circular fins, respectively, had the maximum thermal performance compared with no fin, $1 \mathrm{~mm}, 3 \mathrm{~mm}$ and $4 \mathrm{~mm}$ fin thickness PCM-filled heat sinks. Further, Ali et al. [27] conducted the experimental study using $2 \mathrm{~mm}$ fin thickness pin-fin heat sink to study the constant and intermittent operation conditions. The results revealed that intermittent operating modes showed the maximum operation duration by increasing the operation cycles. Ashraf and his co-authors [28, 29, 30] used the various PCMs of different meting temperature and latent-heat fusion and filled in circular and square pin-fin heat sink having inline and staggered fin distribution. Results revealed the best cooling performance of inline arrangement as compared to staggered for both circular and square pin-fins heat sinks.

This research activity presents the numerical simulation of finned heat sinks using different fin thickness of $2 \mathrm{~mm}$ and $3 \mathrm{~mm}$ considering constant fin volume fraction of $9 \%$ resulting in different fin numbers. Both heat sinks are filled with n-eicosane as the PCM and three different heating power levels of 4,5 and $6 \mathrm{~W}$ are applied at the heat sink base to explore the thermal enhancement performance of PCM based finned heat sinks. This will eventually provide a better picture to select the optimum configuration of PCM based finned heat sink for the solution of electronic devices as passive cooling technology.

\section{Geometric and Mathematical description}

\subsection{Physics of the problem}

In present study, the PCM based finned heat sinks of $2 \mathrm{~mm}$ and $3 \mathrm{~mm}$ fin thickness, which was experimentally investigated by Arshad et al. [22, 23] and Ashraf et al. [28, 29], were numerically modelled to explore the thermal performance of heat sink by varying input parameters. The heat sinks were made of aluminium with constant volume fraction of $9 \%$ which are acting as TCEs embedded with the PCM namely n-eicosane and with fin height of $20 \mathrm{~mm}$. The volume fraction of TCEs denoted by $\gamma$ is calculated using Eq. 1, which is 
actually the ratio of volume occupied by the fins to the total empty volume of heat sink.

$$
\gamma=\frac{V_{T C E}}{V_{H S}}
$$

In recent experimental research investigations, Baby and Balaji [31] and recently Arshad and his co-authors [22, 23, 26] and Ashraf et al. 228, 29] reported that a finned heat sink of volume fraction of $9 \%$ provided the best thermal performance for passive thermal management of portable electronic devices. The system is designed based on the average dimensions of portable hand-held electronic devices. The heat sink were insulated from all sides to prevent any heat loss to the surrounding during operation. The top surface of the heat sink was covered with perspex sheet, to provide the insulation and to visualize the physical change in solid-liquid interface of PCM in melting and solidification phases. The schematic of the physical domain studied in this paper is illustrated in Figure 1. In the system, 2D geometry of the both heat sinks is considered having fin thickness of $2 \mathrm{~mm}$ and 3 $\mathrm{mm}$ with adiabatic walls and a heat flux is implemented at the bottom of the system. The dimensions the physical domain are mentioned in Table 1 . The thermophysical properties of used PCM (n-eicosane) and aluminium are listed in Table 2.

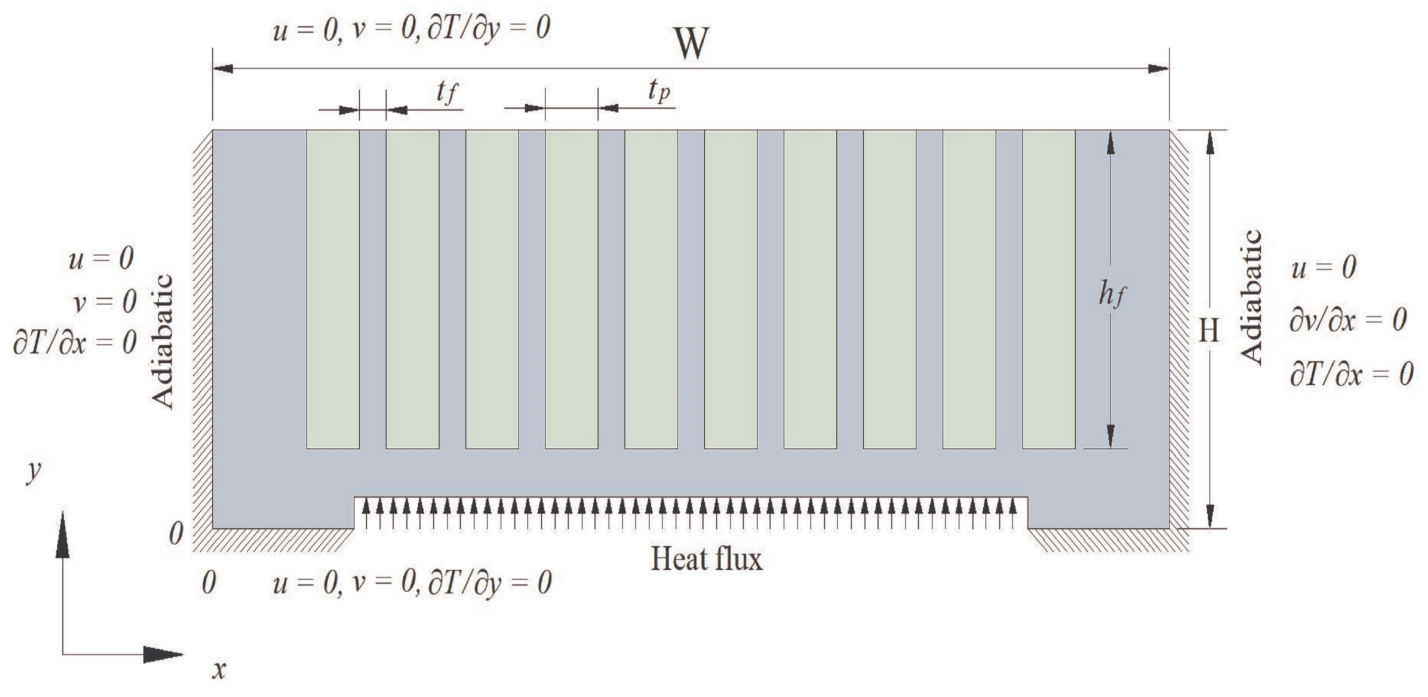

Figure 1: Schematic diagram of the physical domain used in current study.

\subsection{Governing equations}

The governing equations are expressed based on the problem under consideration in current study, as shown in Figure 1. The enthalpy-porosity method is adopted to model the effect of phase transition in the PCM based finned heat sink. The conjugate heat transfer 
Table 1: Dimensions of heat sinks.

\begin{tabular}{|c|c|}
\hline Parameter & Dimensions $(\mathrm{mm})$ \\
\hline $\mathrm{W}$ & 72 \\
\hline $\mathrm{H}$ & 25 \\
\hline$h_{f}$ & 20 \\
\hline$t_{f}$ & $2 \& 3$ \\
\hline
\end{tabular}

Table 2: Thermophysical properties of PCM and TCE.

\begin{tabular}{|c|c|c|}
\hline Property & n-Eicosane & Aluminium \\
\hline$T_{m}(\mathrm{~K})$ & 309.5 & - \\
\hline$T_{s}(\mathrm{~K})$ & 308.5 & - \\
\hline$T_{l}(\mathrm{~K})$ & 310.5 & - \\
\hline$L(\mathrm{~J} / \mathrm{kg})$ & 241,000 & - \\
\hline$c_{p}(\mathrm{~J} / \mathrm{kg} . \mathrm{K})$ & 2050 & 871 \\
\hline$\rho\left(\mathrm{kg} / \mathrm{m}^{3}\right)$ & 790 & 2719 \\
\hline$k(\mathrm{~W} / \mathrm{m} . \mathrm{K})$ & 0.23 & 202.4 \\
\hline$\mu(\mathrm{Pa} . \mathrm{s})$ & 0.00355 & - \\
\hline$\beta(1 / \mathrm{K})$ & 0.0001 & - \\
\hline
\end{tabular}

has been solved using continuity, momentum and energy equations. For the phase transition problem "melting and solidification" model has been applied. The following assumptions are taken to model the PCM based finned heat sink in present numerical investigation [32, 33, 34]:

- Initially, the PCM and heat sink are at the melting temperature of PCM.

- The heat sink remains in solid-state and absorbs the sensible heat only.

- The material of heat sink is homogeneous and isotropic.

- Local thermal equilibrium exists between the fins and liquid PCM.

- Thermophysical properties of PCM and fins are remained constant with temperature and phase.

- The liquid PCM is assumed to be laminar, unsteady, incompressible Newtonian fluid and subjected to the Boussinesq approximation.

- The volume change of PCM is negligible during the melting and solidification.

- The radiative heat transfer is negligible.

The following governing conservation equations for mass, momentum and energy can be written based the above assumptions: 


\section{Mass conservation:}

$$
\frac{\partial u}{\partial x}+\frac{\partial v}{\partial y}=0
$$

\section{Momentum conservation:}

$$
\begin{gathered}
\rho\left(\frac{\partial u}{\partial t}+u \frac{\partial u}{\partial x}+v \frac{\partial u}{\partial y}\right)=-\frac{\partial P}{\partial x}+\mu\left(\frac{\partial^{2} u}{\partial x^{2}}+\frac{\partial^{2} u}{\partial y^{2}}\right)+S u \\
\rho\left(\frac{\partial v}{\partial t}+u \frac{\partial v}{\partial x}+v \frac{\partial v}{\partial y}\right)=-\frac{\partial P}{\partial y}+\mu\left(\frac{\partial^{2} v}{\partial x^{2}}+\frac{\partial^{2} v}{\partial y^{2}}\right)+\rho_{r e f} g \beta\left(T-T_{r e f}\right)+S v
\end{gathered}
$$

\section{Energy conservation:}

$$
\left(\rho c_{p}\right)\left(\frac{\partial T}{\partial t}+u \frac{\partial T}{\partial x}+v \frac{\partial T}{\partial y}\right)=k\left(\frac{\partial^{2} T}{\partial x^{2}}+\frac{\partial^{2} T}{\partial y^{2}}\right)+S_{h}
$$

where, $P$ is the pressure, $g$ is the gravitational acceleration, $\rho$ is the density, $\mu$ is the dynamic viscosity, $\rho c_{p}$ is the thermal capacitance, $k$ is the thermal conductivity, and $t$ is the time, $u$ and $v$ are the velocity components in $x$ and $y$ directions, respectively. Due to the direction of gravitational acceleration in the negative $y$-direction, the Boussinesq approximation is added as the sixth term by $\rho_{\text {ref }} g \beta\left(T-T_{\text {ref }}\right)$ [35, 36]. The value of $\beta=0.001 K^{-1}$ has been chosen based on the analysis of the detailed data reported by Humphries and Griggs [37. The source term $S$ in momentum equation, Equations 3 and 4 can be expressed as follows:

$$
S=-A_{m}(\varphi)
$$

where is $A_{m}(\varphi)$ is the "porosity function" defined by Brent et al. [38] which fulfil "the basic principle is gradually to reduce the velocities from a finite value in liquid, to zero in full solid, over the computational calls that are changing the phase". Thus, nth fluid cells which are undergoing the mushy-zone phase change, $A_{m}(\varphi)$ is defined as follows to make the momentum equation to mimic Carman-Kozeny equations for flow in porous media:

$$
A_{m}(\varphi)=-C \frac{(1-\varphi)^{2}}{\left(\varphi^{3}-b\right)}
$$

where $b=0.001$ is merely a computational constant used to avoid division by zero. The constant $C$ is reflecting the morphology of the melting front which controls the degree of 
penetration of the convection flied into the mushy-zone phase change. The value of $C=10^{5}$ is taken in present study as recommended in several studies [11, 12, 39]. Furthermore, a mushy region lies between the liquid fraction 0 and 1 . The $\varphi$ can be defined as:

$$
\varphi=\frac{\Delta H}{L}= \begin{cases}0 & \text { if } T<T_{s} \\ \frac{T-T_{s}}{T_{l}-T_{s}} & \text { if } T_{s}<T<T_{l} \\ 1 & \text { if } T<T_{l}\end{cases}
$$

The total enthalpy of the PCM is the summation of sensible and latent heat defined as:

$$
H=h+\Delta H
$$

where $h$ is the sensible enthalpy which is defined as follows:

$$
h=h_{r e f}+\int_{T_{r e f}}^{T} c_{p} d T
$$

and $\Delta H$ is the fractional latent heat of the PCM that may vary between 0 for solid and $L$ (latent heat of fusion) for liquid which is expressed as:

$$
\Delta H=\varphi L
$$

The $S_{h}$ is the energy source term in Equation 3 represents the latent heat storage due to melting and it is defined as:

$$
S_{h}=-\frac{\partial(\rho \Delta H)}{\partial t}
$$

Where

$$
\Delta H= \begin{cases}0 & \text { if } T<T_{m} \\ \varphi L & \text { if } T>T_{m}\end{cases}
$$

The mathematical models used for the present simulation can be found in Nayak et al. [7], Wang and Yang [11, 12], Sahoo et al. [16] and Shatikian et al. [8, 39]. They simulated the heat transfer performance of PCM in internal fins. A good agreement was found of numerical results with experimental results reported by Fok et al. [40] and Hosseinizadeh et al. [41]. Therefore, current method is used to simulate the pin-fin heat sink filled with 
PCM a LHSU.

\subsection{Initial and boundary conditions}

The initial and boundary conditions are referenced to the experimental study by Arshad et al. [23, 22, 26] and Ashraf et al. [28, 29]. The schematic of physical domain for the $2 D$ case used in this study is shown in Figure 1. The outer boundary walls are defined as an adiabatic boundary condition because the outer sides of heat sink are insulated with thermal insulation material to prevent the heat loss towards the surrounding in experimentation. Since, the phase change phenomenon is occurring inside the PCM based finned heat sink in transient mode. The initial and boundary conditions applied in the present case are as follows to solve the governing equations:

1. Initial condition

$t=0, T=T_{i n i}=298 K, f_{l}=0$

The following boundary conditions are applied for the solution of governing equations:

2. No slip condition at the walls, i.e. $u=v=0$

3. Heat flux supplied at the bottom,

$$
\left.\frac{\partial T}{\partial y}\right|_{\substack{x=11-61 m m \\ y=0}}=-\frac{q}{k}
$$

4. Natural convective boundary condition with ambient at the top wall, i.e.

$$
-\left.k \frac{\partial T}{\partial y}\right|_{y=H}=h\left(T-T_{\infty}\right)
$$

5. Adiabatic boundary condition at side wall and bottom,

$$
\begin{array}{lc}
\left.\frac{\partial T}{\partial x}\right|_{x=0, W}=0 & \text { Along vertical walls } \\
\left.\frac{\partial T}{\partial y}\right|_{\substack{x=0-11,61-72 \\
y=0}}=0 & \text { For bottom }
\end{array}
$$

\subsection{Numerical methodology}

The commercial computational fluid dynamics (CFD) software ANSYS-FLUENT 19.1 was used to conduct the transient simulations in present study. The conservation of mass, momentum and energy equations described in Equation 2,5 are discretized by finite volume method $(\mathrm{FVM})$ with double precision. The conjugate heat transfer has been solved using continuity, momentum and energy equations. For the phase transition problem "melting and solidification" model has been applied. The solidification and melting model is based on the enthalpy-porosity method. In this model, instead of explicitly tracking of melt fraction, the liquid volume of each cell represented as liquid fraction. For the pressure-velocity coupling, Semi-Implicit Pressure-Linked Equation (SIMPLE) algorithm has been used of Patanker 
Table 3: Grid independency analysis.

\begin{tabular}{|l|c|c|c|c|c|}
\hline Grid systam & Number of elements & Melting time (s) & Deviation (\%) & Average heat sink temperature (K) & Deviation (\%) \\
\hline Grid A & 18862 & 1945.00 & 0.00 & 319.64 & 0.00 \\
\hline Grid B & 27126 & 1945.00 & 0.00 & 319.59 & 0.01 \\
\hline Grid C & 42418 & 1950.00 & 0.26 & 319.50 & 0.03 \\
\hline Grid D & 73970 & 1955.00 & 0.26 & 319.38 & 0.04 \\
\hline Grid E & 167493 & 1980.00 & 1.28 & 318.80 & 0.18 \\
\hline
\end{tabular}

[42]. For the pressure correction equation, Presto scheme is used while QUICK scheme is employed for the momentum and energy equations [43]. A second order upwind differencing scheme was employed for the discretization of convective terms in momentum and energy equations. Gravity effects were also considered. The convergence criteria are set to $10^{-4}$, $10^{-4}$ and $10^{-6}$ for continuity, momentum and energy equations, respectively. The grid and time independence tests were carried out to avoid their effects on the numerical accuracy. Five different mesh size of elements sizes 18862, 27126, 42418, 73970 and 167493 were investigated. The result of liquid-fraction variations of each element size is presented in Figure 2a. The melting time and average heat sink base temperature for each gird size are presented in Table 3. The results reveals that the maximum deviation in melting time and average heat sink temperature are obtained of $1.28 \%$ and $0.18 \%$, respectively. The three time-steps of $\Delta t=0.05,0.1$ and $0.2 \mathrm{~s}$ are examined and result is presented in Figure 2b. The results illustrate no significance change is observed in liquid fraction for different time-step sizes. The reason is that PCM upfront velocity and thermal front movement are low, reflecting a low Peclet number and Courant number situation. After comparisons of results, the mesh with 42418 elements and time-step of $\Delta t=0.1 \mathrm{~s}$ were selected in the current study for further simulations. To compromise the accuracy and cost, the mesh size of 42418 elements is selected.

\subsection{Non-dimensional equations}

The dimensionless analysis is performed in order to normalize the phase change heat transfer process and melting phenomenon of the n-eicosane embedded into the finned heat sinks.

The dimensionless average heat sink base temperature $(\theta)$ is defined to express the temperature distribution while melting inside the heat sink [44].

$$
\theta=\frac{k\left(T-T_{i n i}\right)}{q h_{f}}
$$

The dimensionless heat flux $(\bar{Q})$ is defined to express the generalized effect of heating 


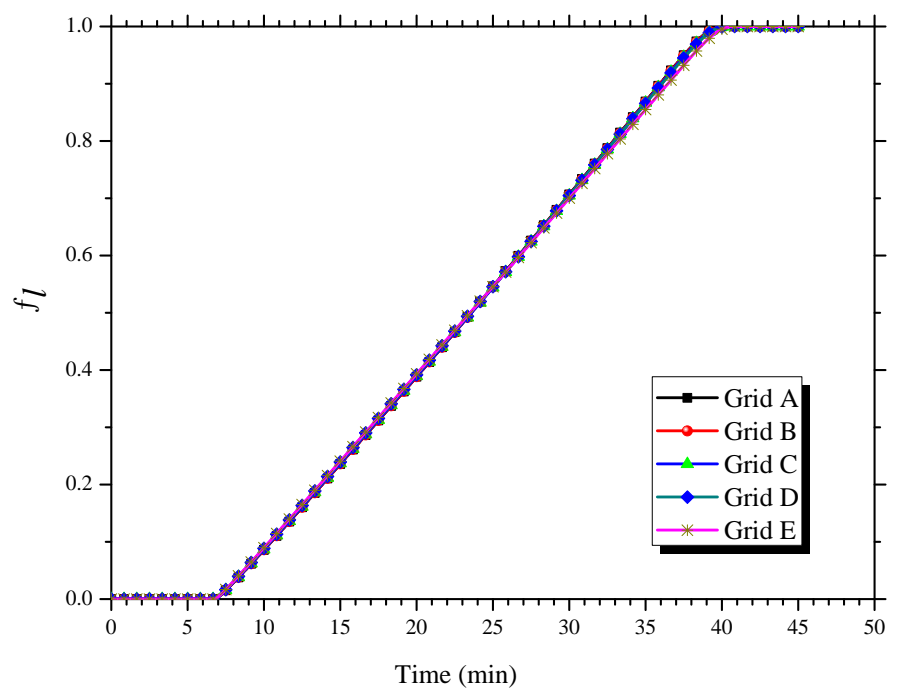

(a)

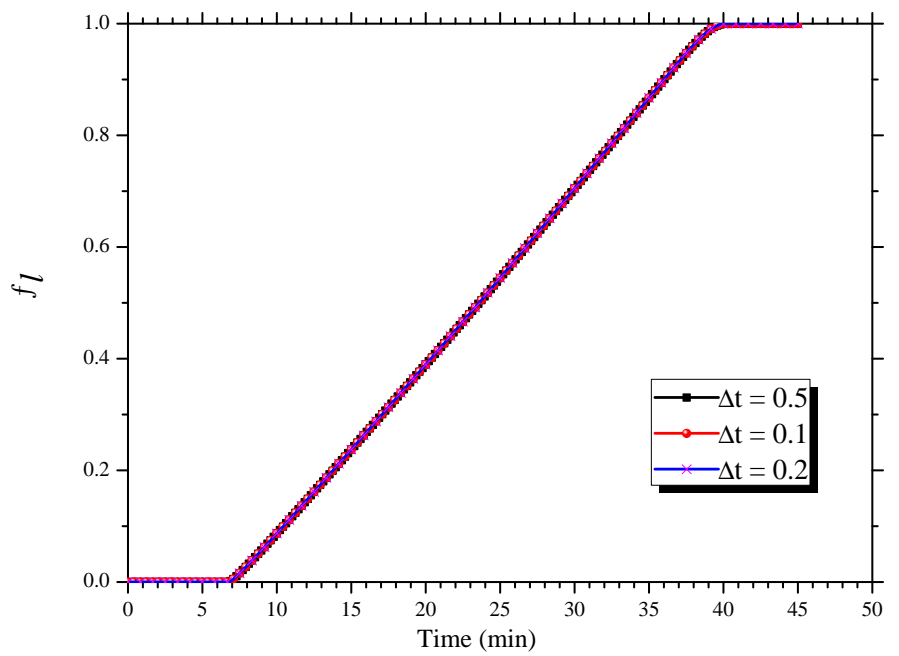

(b)

Figure 2: (a)-Grid and (b) time-step independency test results.

power during the PCM phase transition inside the heat sink which averaged over the heat sink base.

$$
\bar{Q}=\frac{q h_{f}}{k\left(T_{m}-T_{i n i}\right)}
$$

The non-dimensional number utilized in transient heat conduction problems is Fourier number $\left(F_{O}\right)$ which is defined as the ratio between the diffusive transport and the energy storage. Fo depicts the time for diffusion of heat across the PCM thickness and it can be calculated as follows [32, 45]:

$$
F_{O}=\frac{\alpha t}{h_{f}^{2}}
$$


Stefan number (Ste) represents amount of superheating which is experienced by the liquidphase of the PCM. While melting, the effect of convection is present only when the Ste number is greater than 1. Ste number is defined as the ratio of the sensible heat to the latent heat, which is defined as [32, 45]:

$$
\text { Ste }=\frac{c_{p} \Delta T}{L}
$$

where

$$
\Delta T=\frac{q h_{f}}{k}
$$

Therefore, Ste number is defined as:

$$
\text { Ste }=\frac{c_{p} q h_{f}}{k L}
$$

The product of Ste and Fo numbers represents the dimensionless time for phase change without convection.

$$
\tau=F_{O} \times S t e=\frac{\alpha t}{h_{f}} \times \frac{c_{p} q}{k L}
$$

To account the effect of free or natural convection heat transfer in molten PCM, Grashof $(G r)$ number or more comprehensively Rayleigh $(R a)$ number is used which is associated with the buoyancy driven flow indicating the ratio of natural convection to conduction heat transfer. For a uniform heat flux, $R a$ based on the fin height as a characteristic length is defined as [32, 45]:

$$
R a^{*}=\frac{\rho^{2} g \beta c_{p} q h_{f}^{4}}{k^{4} \mu}
$$

Heat transfer as a function of dimensionless number is described by modified Nusselt number $\left(N u^{*}\right)$ which presents the time-dependent relationship between the instantaneous heat flux $(q)$ and temperature difference $(\Delta T)$, is defined as [32, 39]:

$$
N u^{*}=\frac{q\left(t_{p} / 2\right)}{\Delta T k}
$$

Where, $\Delta T$ is the temperature difference between the base temperature and melting temperature of the PCM, $t_{p} / 2$ is half-thickness of the PCM layer is chosen as characteristics length 
proposed by Saha and Dutta [32] and Shatikian et al. [39]. The reason to choose the $t_{p} / 2$ as characteristics length is that for tall enclosure, the aspect ratio of fin height and PCM thickness $\left(h_{f} 2 / t_{p}\right)$ of the heat sink cavity is very large, which reduce the effect of convection compared with conduction heat transfer in the PCM domain results is a lower temperature difference between the two consecutive fins. Furthermore, Saha and Dutta [32] reported the range of aspect ratio of fin height and PCM thickness $\left(1.939<h_{f} 2 / t_{p} \leq 5\right)$ for tall enclosures which almost equal to 4.32 and 5.13 for $3 \mathrm{~mm}$ and $2 \mathrm{~mm}$ fin thickness heat sinks. Therefore, the results of $N u^{*}$ number and liquid fraction as a function of FoSteRa based on $t_{p} / 2$ as characteristic length scale are expressed using modified $F_{o}{ }^{*}$ number, Ste ${ }^{*}$ number and $R a^{*}$ number:

$$
\begin{gathered}
F o^{*}=\frac{\alpha t}{\left(t_{p} / 2\right)^{2}} \\
S t e^{*}=\frac{c_{p} q\left(t_{p} / 2\right)}{k L} \\
R a_{t_{p} / 2}^{*}=\frac{\rho^{2} g \beta c_{p} q\left(t_{p} / 2\right)^{4}}{k^{4} \mu}
\end{gathered}
$$

The mentioned dimensionless parameter are employed in various previous studies to define the variation in heat sink temperature and liquid fraction [8, 13, 16, 32, 44].

\section{Model validation}

\subsection{Experimental validation for the heat sink}

The current model is validated with experimental results of a no fin heat sink filled with PCM having the dimension of similar dimensions used in Ashraf et al. [28]. The RT$35 \mathrm{HC}$ was used as a PCM having melting temperature of $35^{\circ} \mathrm{C}$ at a input power level of $5 \mathrm{~W}$. The results of average temperature of heat sink was compared of both numerical and

experimental cases, as shown in Figure 3. The results of both numerical and experimental results showed a good agreement and revealed that the present numerical model can be used for further simulations.

\subsection{Validation for the phase change process}

To validate and ensure the accuracy of the numerical approach, the average temperature and liquid fraction of RT-58 PCM in a horizontal triples tube LHS system with internal- 


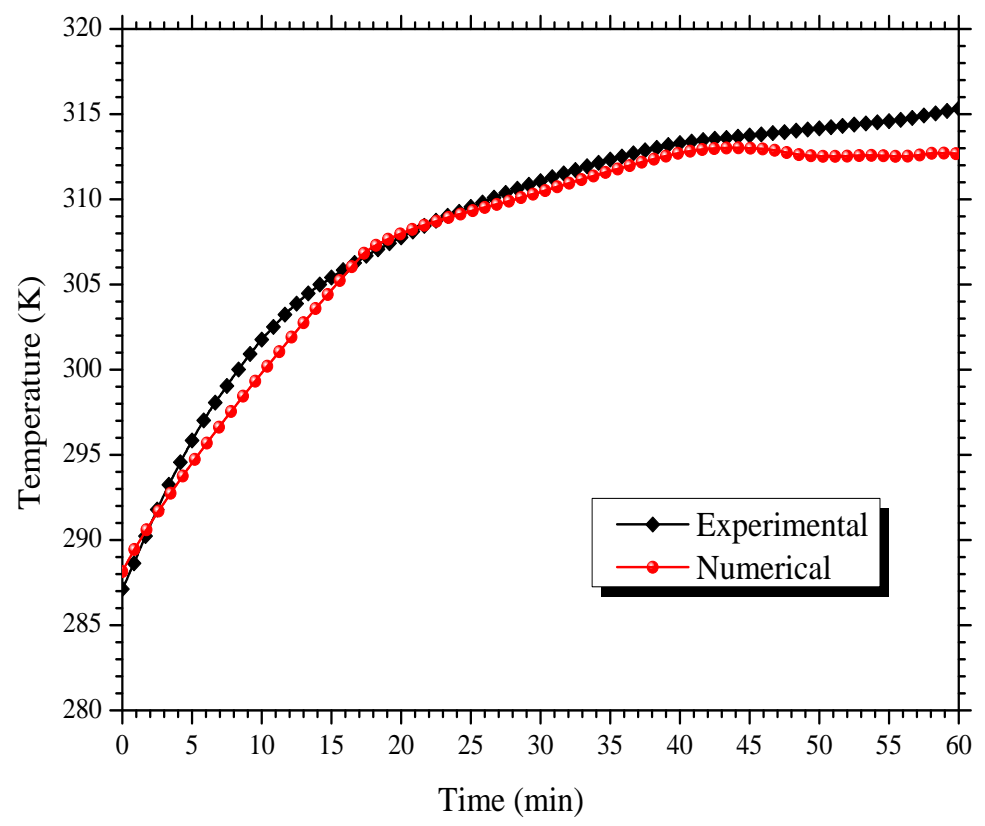

Figure 3: Validation of present simulation with experimental results with no fin heat sink.

external fins were determined and compared with the experimental and numerical results presented by Mat et al. [46]. For the studied geometry, the initial and wall temperatures were considered $27{ }^{\circ} \mathrm{C}$ and $120{ }^{\circ} \mathrm{C}$, respectively, where the inner and outer diameters of the system are 25.4 and $75 \mathrm{~mm}$, respectively. The copper fins have a length of $42 \mathrm{~mm}$ with 1 mm thickness which are heated from the walls as shown. The results of mean temperature and liquid fraction obtained from the present study are shown in Figure 4 and compared with Mat el al. [46], with excellent agreement for both temperature and liquid fraction.

\section{Results and discussion}

\subsection{Temperature and melt-fraction distribution}

Figure 5 presents the transient variation of liquid or melt fraction contours of PCM for 2 $\mathrm{mm}$ fin thickness heat sink at various input power level of $4-6 \mathrm{~W}$ for $10 \mathrm{~min}$ time intervals during melting. The variation in solid-liquid interface can also be depicted from the Figure 5 as well. When the liquid fraction is 0 , the PCM is fully in solid form and when it is 1 the PCM is fully melted. The region between 0 and 1 is known as the transition region where PCM exhibited both solid and liquid phases called mushy zone. The melting of PCM increases with the increase of time. With the increase of input heat flux, the melting region of PCM increases and therefore, a higher value of liquid fraction is obtained at an identical time. In addition, the melting of PCM increases with the increase of time at an identical input heat flux, as expected. The rate of PCM melting lower at low input heat flux as 


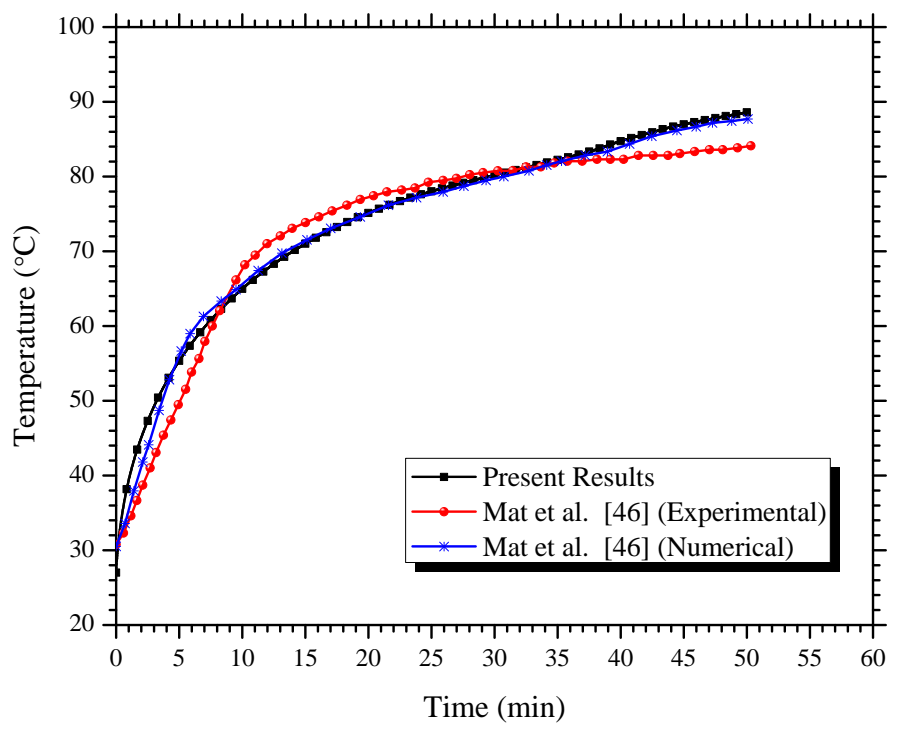

(a)

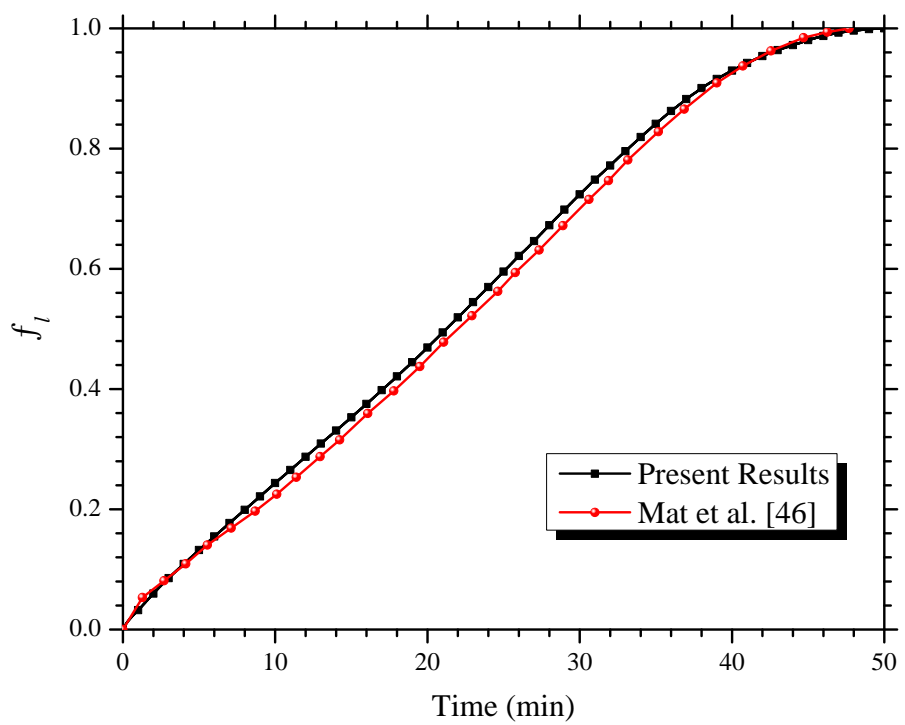

(b)

Figure 4: Validation of the present results for (a) average temperature and (b) liquid fraction of PCM.

compared to high heat flux as the time increases which is due to the rapid heat transfer into the PCM through fins, results in a higher rate of PCM melting. It can be seen from Figure 5 that at $4 \mathrm{~W}$, the PCM did not fully melt even after 40 min of heating. Contrarily, it is fully melted at $5 \mathrm{~W}$ and $6 \mathrm{~W}$ after $40 \mathrm{~min}$. It is revealed that the higher the heat flux, higher the heat transfer rate results in higher the liquid fraction rate or melting rate of the PCM in a finned based heat sink.

The rate of heat transfer in a PCM filled finned heat sink can been from temperature contours shown in Figure 6, which shows the distribution of temperature inside in the 2 $\mathrm{mm}$ and $3 \mathrm{~mm}$ fin thickness finned heat sink for different time steps at a power level of 


\begin{tabular}{lllllllllll}
\hline & 0.1 & 0.2 & 0.3 & 0.4 & 0.5 & 0.6 & 0.7 & 0.8 & 0.9 & 1
\end{tabular}

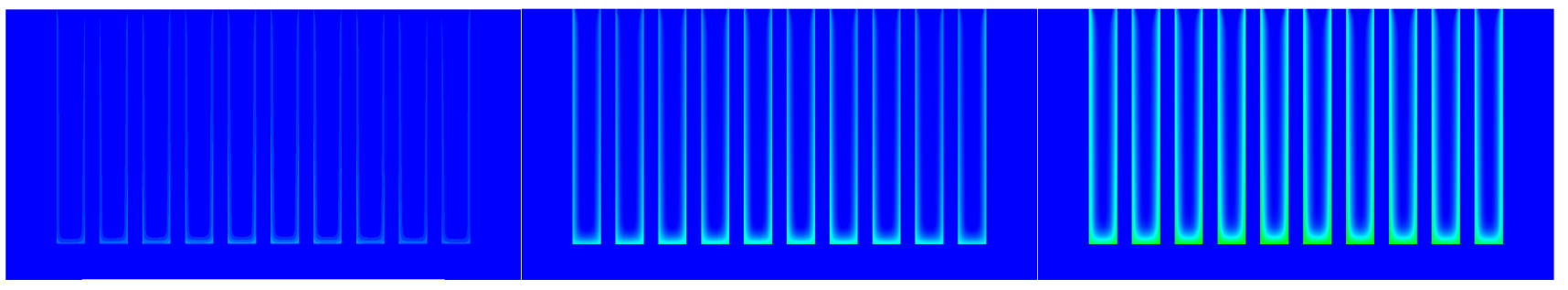

(a) $4 \mathrm{~W}, 10 \mathrm{~min}$

(b) $5 \mathrm{~W}, 10 \mathrm{~min}$

(c) $6 \mathrm{~W}, 10 \mathrm{~min}$

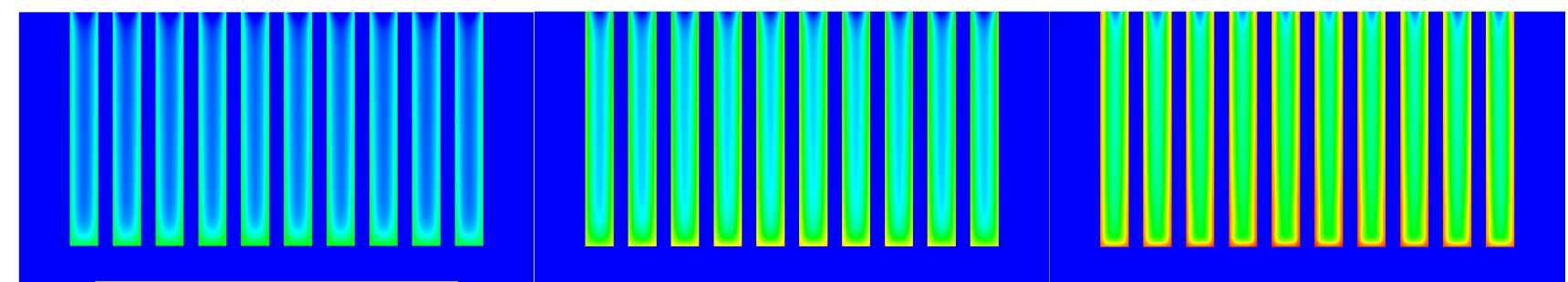

(d) $4 \mathrm{~W}, 20 \mathrm{~min}$

(e) $5 \mathrm{~W}, 20 \mathrm{~min}$

(f) $6 \mathrm{~W}, 20 \mathrm{~min}$

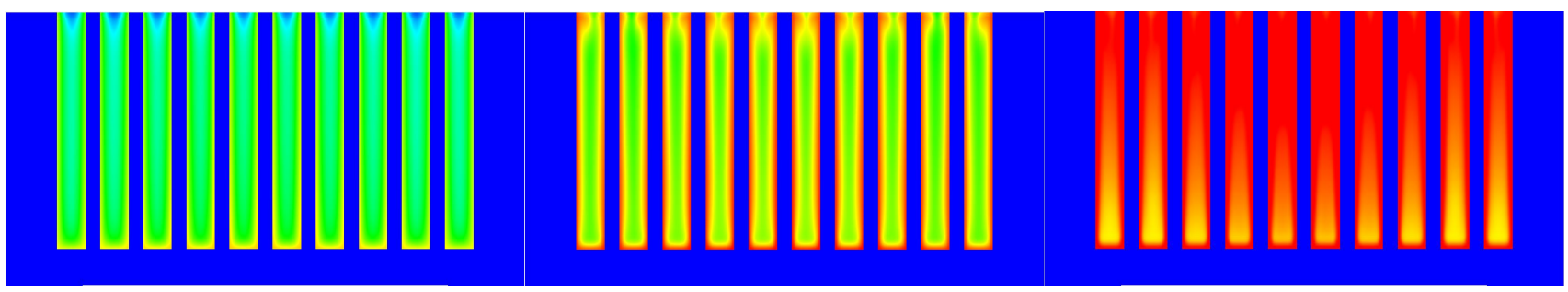

(g) 4W, $30 \mathrm{~min}$

(h) $5 \mathrm{~W}, 30 \mathrm{~min}$

(i) $6 \mathrm{~W}, 30 \mathrm{~min}$

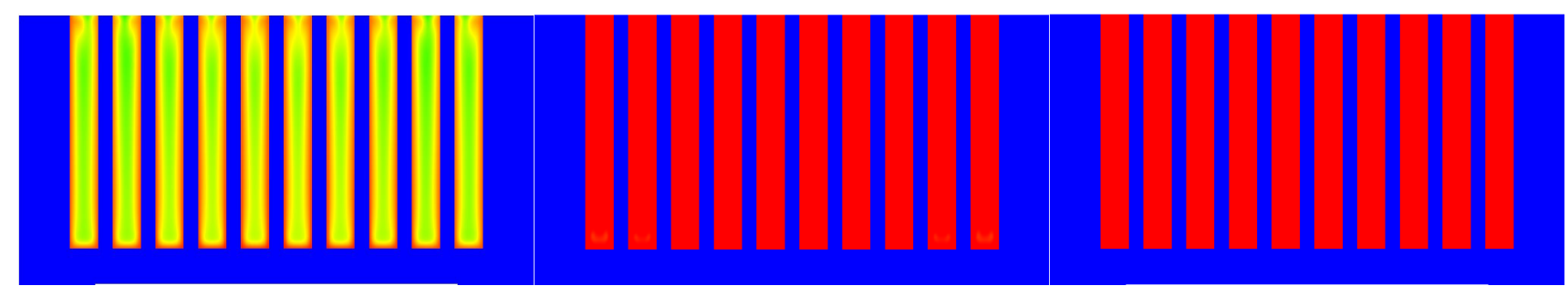

(j) $4 \mathrm{~W}, 40 \mathrm{~min}$

(k) $5 \mathrm{~W}, 40 \mathrm{~min}$

(l) 6W, $40 \mathrm{~min}$

Figure 5: Variation of liquid fraction of $2 \mathrm{~mm}$ fin thickness at various time periods and input heat fluxes. 
$5 \mathrm{~W}$ during melting. At a constant input power level, it can be seen clearly that the rate of temperature rise is higher in $2 \mathrm{~mm}$ fin thickness heat sink as compared $3 \mathrm{~mm}$ fin thickness heat sink in all times. For example, the temperature varies from $317.82 \mathrm{~K}$ to $319.58 \mathrm{~K}$ for $2 \mathrm{~mm}$ fin thickness heat sink at $45 \mathrm{~min}$, whereas it varies from $315.7-317.5 \mathrm{~K}$ for the case of $3 \mathrm{~mm}$ fin thickness heat sink. The higher temperature rise in $2 \mathrm{~mm}$ fin thickness heat sink is due the more number of fins compared to the $3 \mathrm{~mm}$ fin thickness heat sink. Furthermore, the penetration of heat in PCM region is more in case of $2 \mathrm{~mm}$ fin thickness heat sink causing a shorter melting time which can be seen in Figure 6 especially at time $30 \mathrm{~min}$.

A further comparison of liquid fraction contours for both fin thickness heat sinks can be seen from Figure 7. The finned heat sink of $3 \mathrm{~mm}$ fin thickness has the lower rate of PCM melting due to the higher heat transfer area, optimum number and distribution of fins. The lower rate of PCM melting of $3 \mathrm{~mm}$ fin thickness heat sink enhances to absorb and transfer the heat more uniformly and effectively towards the ambient, keeping the base temperature of heat sink at lower level thus resulting in more efficient thermal cooling. Similar findings of $2 \mathrm{~mm}$ and $3 \mathrm{~mm}$ fin thickness finned heat sink has been reported in Ref. [26].

The heating phenomenon inside the heat sink can be seen from the velocity vectors shown in Figure 8, which shows the formation of vortices at the base and top of the PCM zone between the two consecutive fins. The direction of velocity vectors show that liquid PCM moves from bottom to top close to the walls and then converge at centre of the PCM zone while heating at the base. The formations of vortices are in two main circulating patterns of the liquid PCM because of natural convection and direction of gravity.

\subsection{Temperature and melt-fraction variation}

The results are presented by comparing the temperature difference-time variations of 2 $\mathrm{mm}$ and $3 \mathrm{~mm}$ fin thickness finned heat sink at different power levels in Figure 9. Since the initial temperature is fixed which is equal to the ambient conditions, a temperature difference is reported instead of temperature. The temperature difference $\left(\Delta T=T-T_{\text {ini }}\right)$ represents the difference between the temperature of heated base of heat sink and initial temperature. As expected, the lower the power level, the higher the time needed to fully melt the n-eicosane which happens when the PCM temperature rises above the melting point temperature. The maximum heat sink base temperature difference reaches at 21.68 ${ }^{\circ} \mathrm{C}$ and $18.31{ }^{\circ} \mathrm{C}$ at $4 \mathrm{~W}, 40.32{ }^{\circ} \mathrm{C}$ and $37.67{ }^{\circ} \mathrm{C}$ at $5 \mathrm{~W}$, and $57.51{ }^{\circ} \mathrm{C}$ and $55.24{ }^{\circ} \mathrm{C}$ at $6 \mathrm{~W}$ 


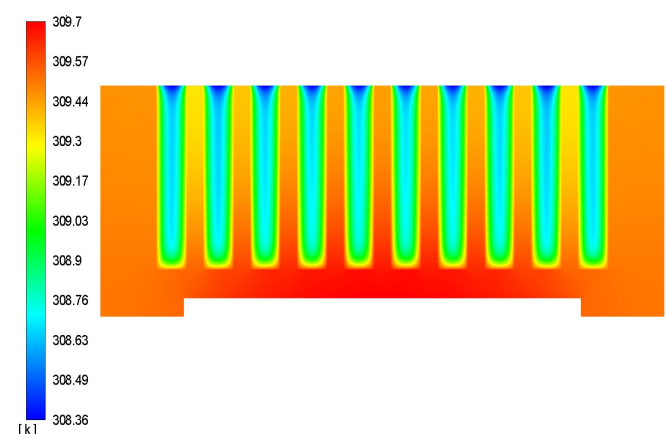

(a) $2 \mathrm{~mm}, 15 \mathrm{~min}$

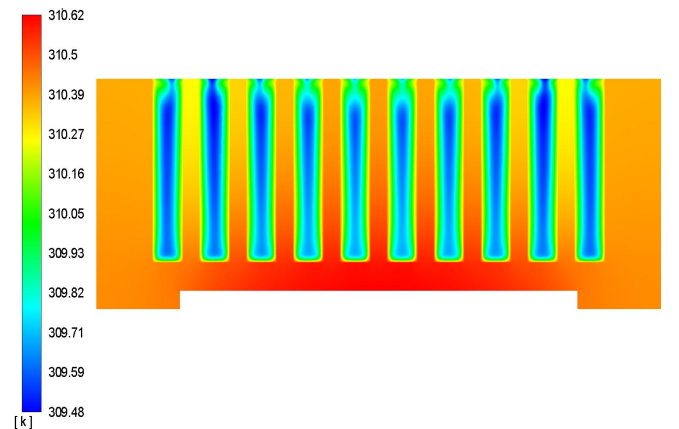

(c) $2 \mathrm{~mm}, 30 \mathrm{~min}$

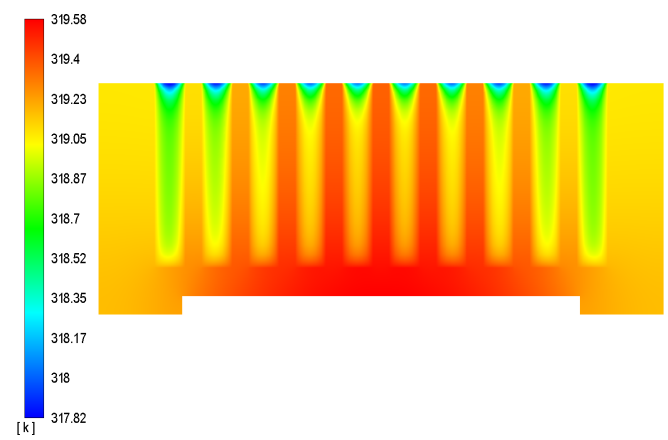

(e) $2 \mathrm{~mm}, 30 \mathrm{~min}$

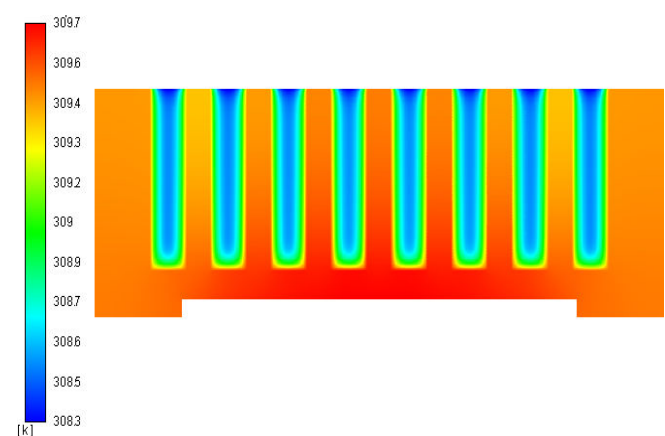

(b) $3 \mathrm{~mm}, 15 \mathrm{~min}$

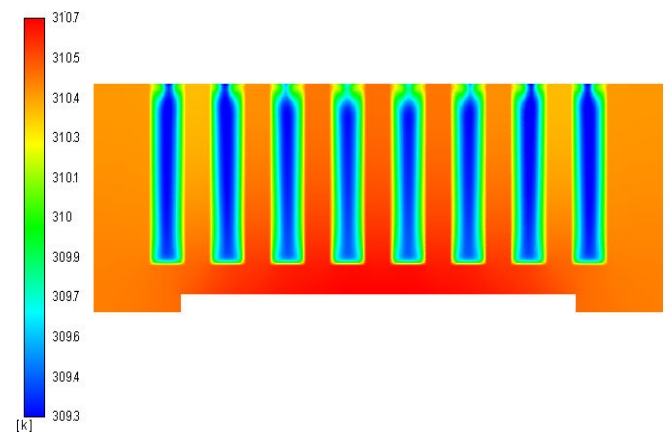

(d) $3 \mathrm{~mm}, 30 \mathrm{~min}$

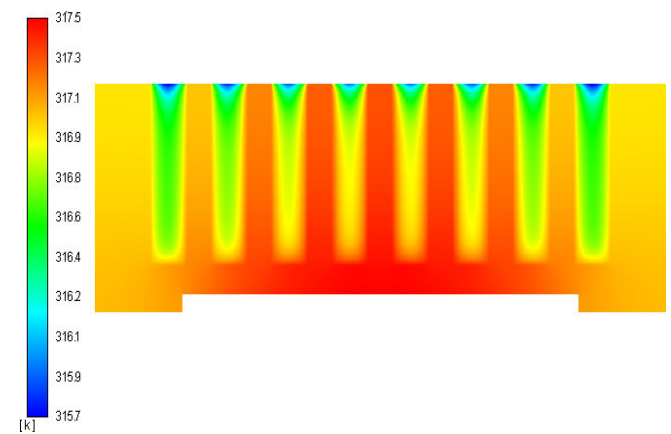

(f) $3 \mathrm{~mm}, 30 \mathrm{~min}$

Figure 6: Comparison of isotherms contours at various time period of $2 \mathrm{~mm}$ and $3 \mathrm{~mm}$ fin thickness cases at power level of $5 \mathrm{~W}$. 
Liquid Fraction

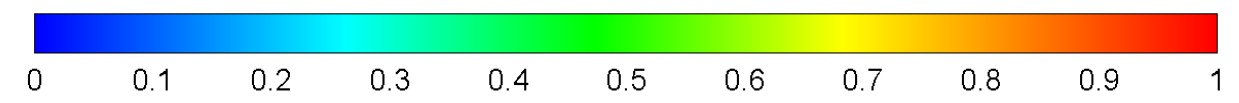

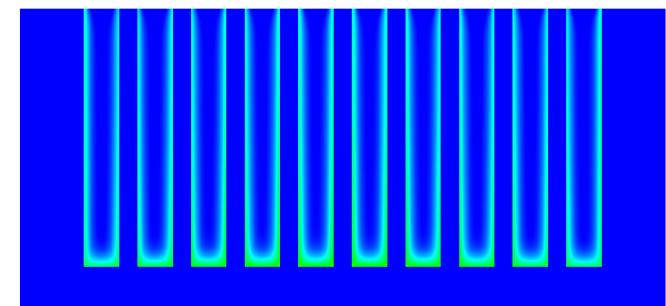

(a) $2 \mathrm{~mm}, 10 \mathrm{~min}$

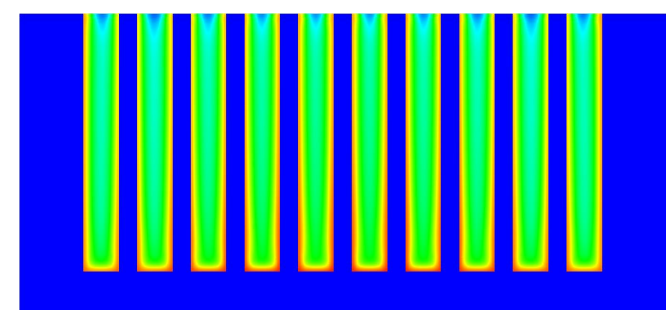

(c) $2 \mathrm{~mm}, 20 \mathrm{~min}$

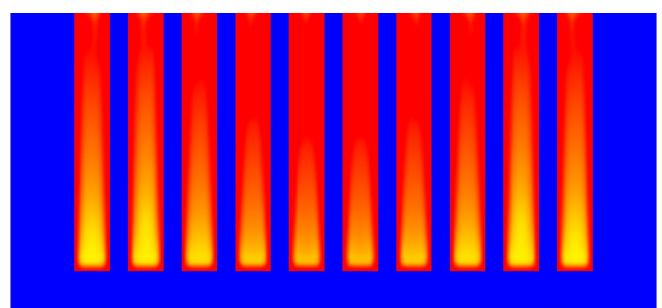

(e) $2 \mathrm{~mm}, 30 \mathrm{~min}$

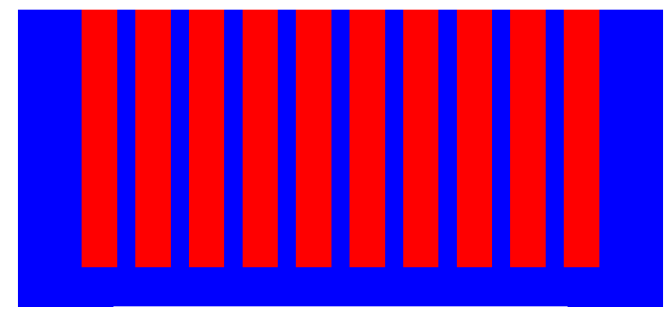

(g) $2 \mathrm{~mm}, 40 \mathrm{~min}$

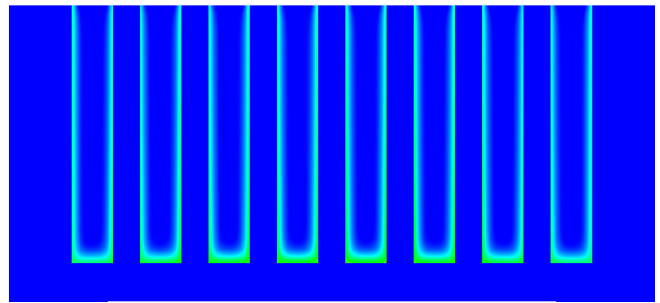

(b) $3 \mathrm{~mm}, 10 \mathrm{~min}$

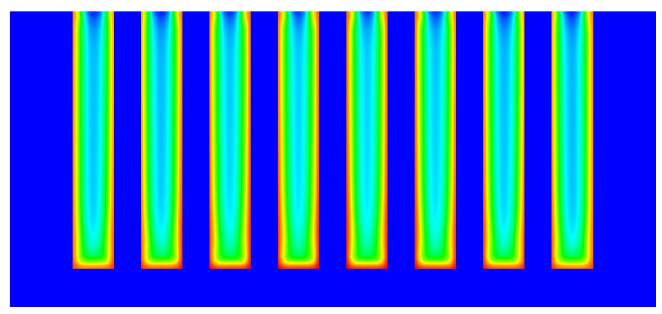

(d) $3 \mathrm{~mm}, 20 \mathrm{~min}$

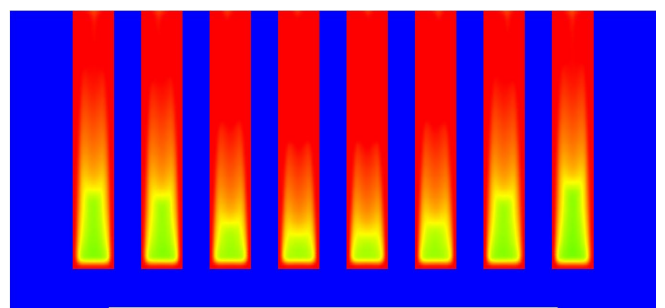

(f) $3 \mathrm{~mm}, 30 \mathrm{~min}$

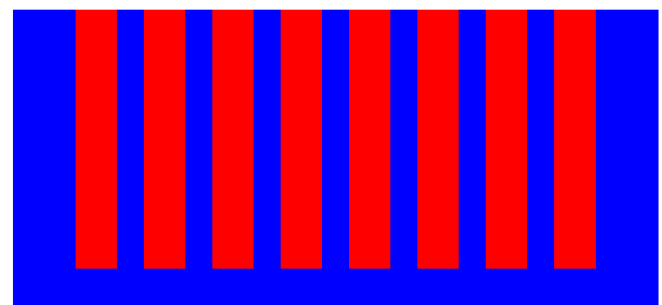

(h) $3 \mathrm{~mm}, 40 \mathrm{~min}$

Figure 7: Comparison of liquid fractions contours at various time period of $2 \mathrm{~mm}$ and $3 \mathrm{~mm}$ fin thickness cases at power level of $6 \mathrm{~W}$. 


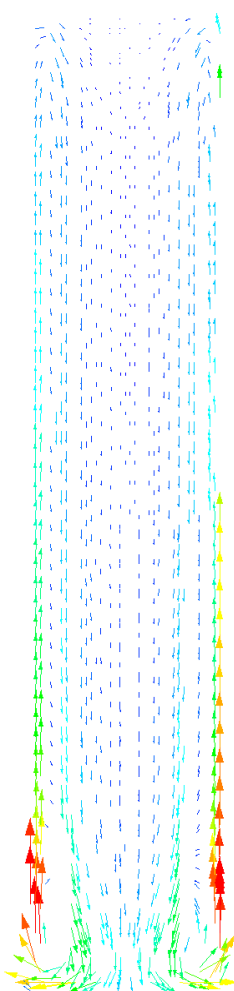

(a) $15 \mathrm{~min}$

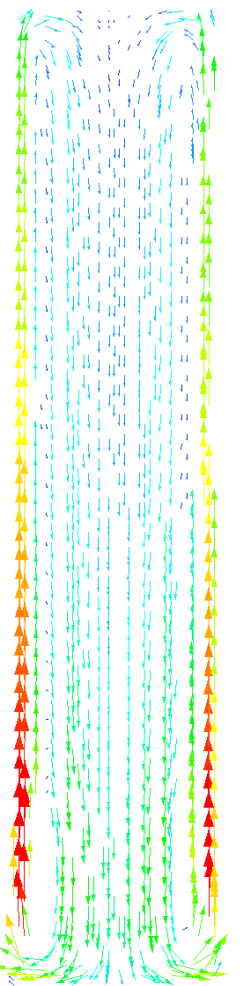

(b) $20 \mathrm{~min}$

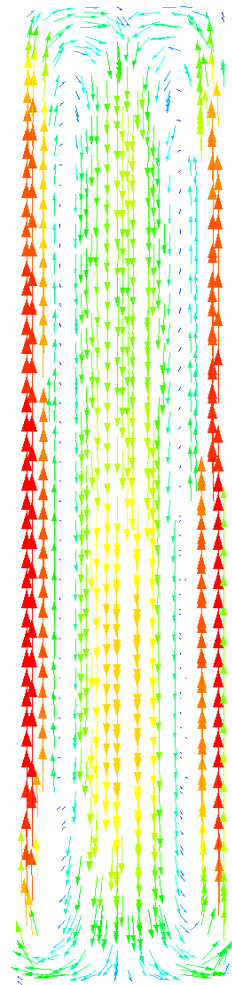

(c) $25 \mathrm{~min}$

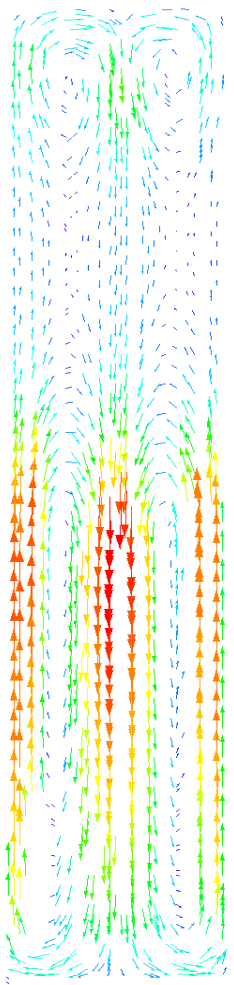

(d) $30 \mathrm{~min}$

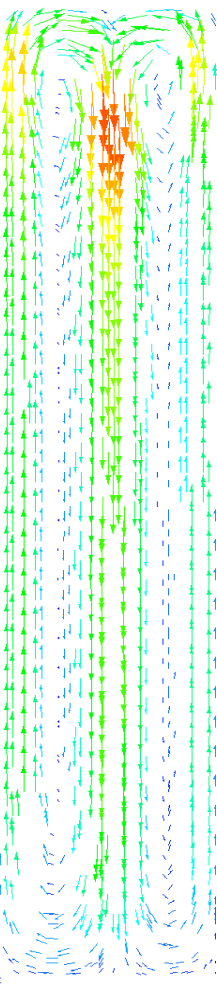

(e) $35 \mathrm{~min}$

Figure 8: Velocity vectors of PCM melting within the fins.

with $2 \mathrm{~mm}$ and $3 \mathrm{~mm}$ fin thickness finned heat sink, respectively. The melt fraction curves of both fin thickness finned heat sink at different power levels are shown in Figure 9. At each power level, the melt fraction of different configurations finishes uniformly due to the natural convection heat transfer within the melt region and uniform distribution of the fins. In addition, the case of $3 \mathrm{~mm}$ fin thickness takes a higher time to complete the melting phase compared with the $2 \mathrm{~mm}$ fin thickness finned heat sink. The melting times are $2565 \mathrm{~s}$ and $2730 \mathrm{~s}$ at $4 \mathrm{~W}, 1925 \mathrm{~s}$ and $1745 \mathrm{~s}$ at $5 \mathrm{~W}$, and $1550 \mathrm{~s}$ and $1605 \mathrm{~s}$ at $6 \mathrm{~W}$ for $2 \mathrm{~mm}$ and $3 \mathrm{~mm}$ fin thickness finned heat sink, respectively. Hence, the selection of PCM based heat sink as a passive cooling media is based on the operating power of the electronic device. At higher input power level, more PCM or a PCM with higher latent heat of fusion is required, which can prolong the operating duration at comfortable temperature level. Furthermore, it can be seen from Figure 10 that at each power level, the configuration of $3 \mathrm{~mm}$ fin thickness finned heat sink takes more time to complete the solid-liquid phase change process compared with $2 \mathrm{~mm}$ fin thickness finned heat sink when fully filled with PCM. The higher time to complete the melting process leads to lower the base temperature of the heat sink and thus 3 mm fin thickness finned heat sink has the best thermal performance to enhance the passive cooling capability of electronic devices filled with PCMs. 


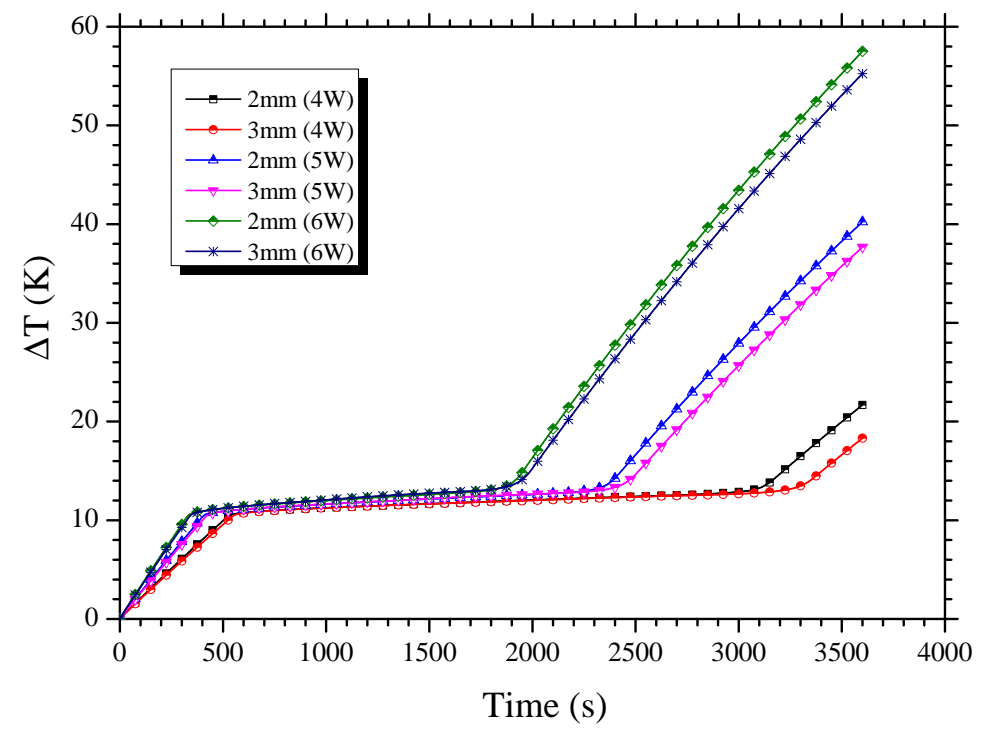

Figure 9: Temperature-time history of $2 \mathrm{~mm}$ and $3 \mathrm{~mm}$ fin thickness PCM filled heat sinks at different heat fluxes.

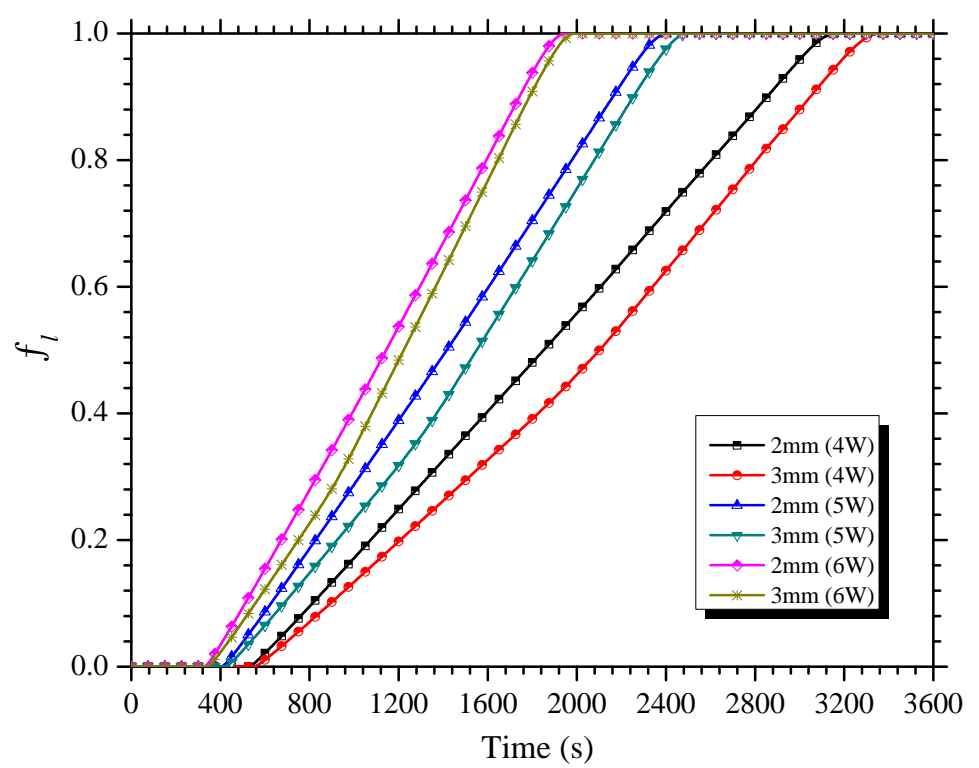

Figure 10: Melt fraction curves of $2 \mathrm{~mm}$ and $3 \mathrm{~mm}$ fin thickness PCM filled heat sinks at different heat fluxes.

\subsection{Dimensionless temperature, melt-fraction and heat transfer analysis}

Figure 11 illustrates the distribution of dimensionless average heat sink base temperature $(\theta)$ as a function Fourier number $(F o)$ at different dimensionless heat fluxes $(\bar{Q}=12,15$ and 18) for $2 \mathrm{~mm}$ and $3 \mathrm{~mm}$ fin thickness finned heat sink. For a constant $\bar{Q}=12$, the variation in $\theta$ of finned heat sinks shows that uniform distribution of temperature inside the heat sink with the increase in Fo. Then, the rate of temperature enhancement reduces due to an almost constant temperature of the PCM during the phase change and then increases sharply. At a constant $\bar{Q}$, the temperature is almost similar for both $2 \mathrm{~mm}$ and $3 \mathrm{~mm}$ 
thickness of the fins. In addition, the $\theta$ is higher for a lower $\bar{Q}$ during the melting process. However, PCM melting is terminated in a lower $F_{O}$ for a higher $\bar{Q}$ and then $\theta$ increases sharply after the melting process. The reason for this can be explained from Equations 14 and 15. For constant properties of PCM and a constant fin height, Fo number increases and $\theta$ decreases by increasing $\bar{Q}$. However, at constant $\bar{Q}$, the $\theta$ varies with temperature difference $\left(\Delta T=T-T_{i n i}\right)$ and $F_{o}$. Moreover, at a constant $F_{O}$, a higher $\theta$ is achieved for 2 $\mathrm{mm}$ fin thickness compared with $3 \mathrm{~mm}$ case at a constant $\bar{Q}$, which reflects the increase in the phase transition duration from solid to liquid results in improves the thermal performance of heat sink. As shown in Figure 11, Fo alone is not sufficient to express the generalize trend of temperature distribution because of the effect of phase change process. Figure 12 represents the distribution of $\theta$ as a function of dimensionless time $(\tau)$ at different $\bar{Q}$. The similar trends of $\theta$ by varying the $\bar{Q}$, i.e. the at lower $\bar{Q}, \theta$ reaches higher and it takes more time to complete the phase change process during melting. It can been seen from both finned heat sinks, the $\theta$ increases $\Delta T$ increases with the decrease of $\bar{Q}$ at the same $\tau$ due to $\Delta T$ of energy storage increasing constantly [13]. However, when the $\tau$ is larger than 1.25, the $\theta$ increases linearly. This is caused by $\tau$ only covers over the critical point $(\tau=1.25)$, as shown in Figure 12 .

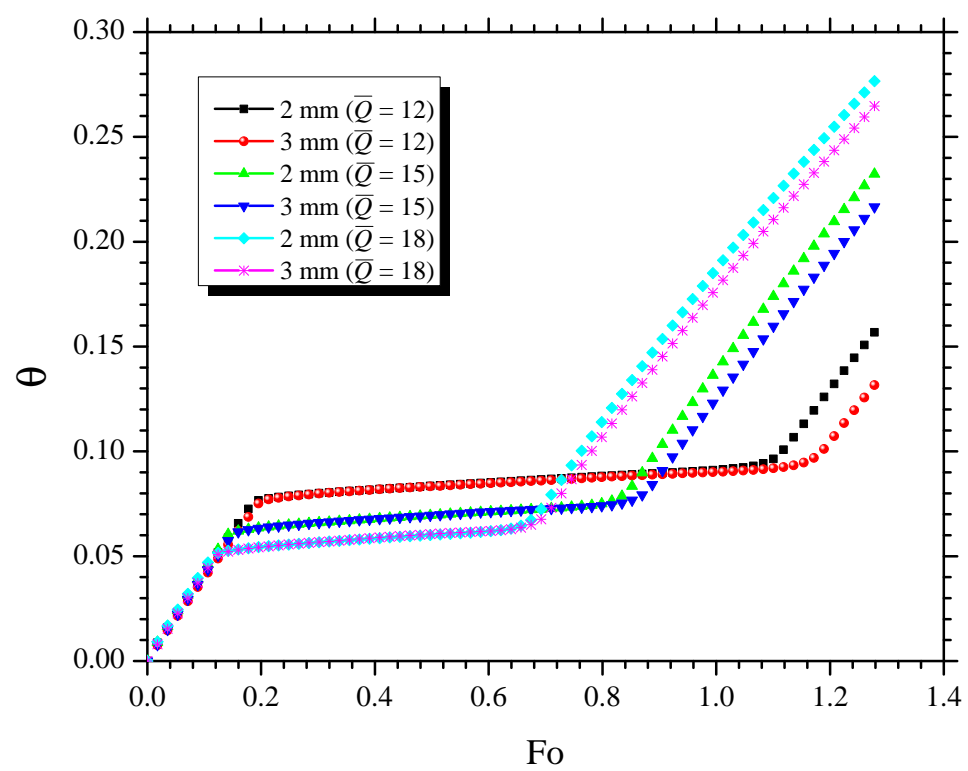

Figure 11: The variation of $\theta$ in terms of Fo for different $\bar{Q}$.

Figure 13 shows the variation of liquid fraction as a function of modified $F o^{*}$ number at different modified Ste $e^{*}$ numbers $\left(S t e^{*}=0.12-0.21\right)$ for both finned heat sinks. It can be seen that the $2 \mathrm{~mm}$ fin thickness finned heat sink has a higher liquid fraction compared to the $3 \mathrm{~mm}$ fin thickness finned heat sink at a constant Ste* Furthermore, the liquid 


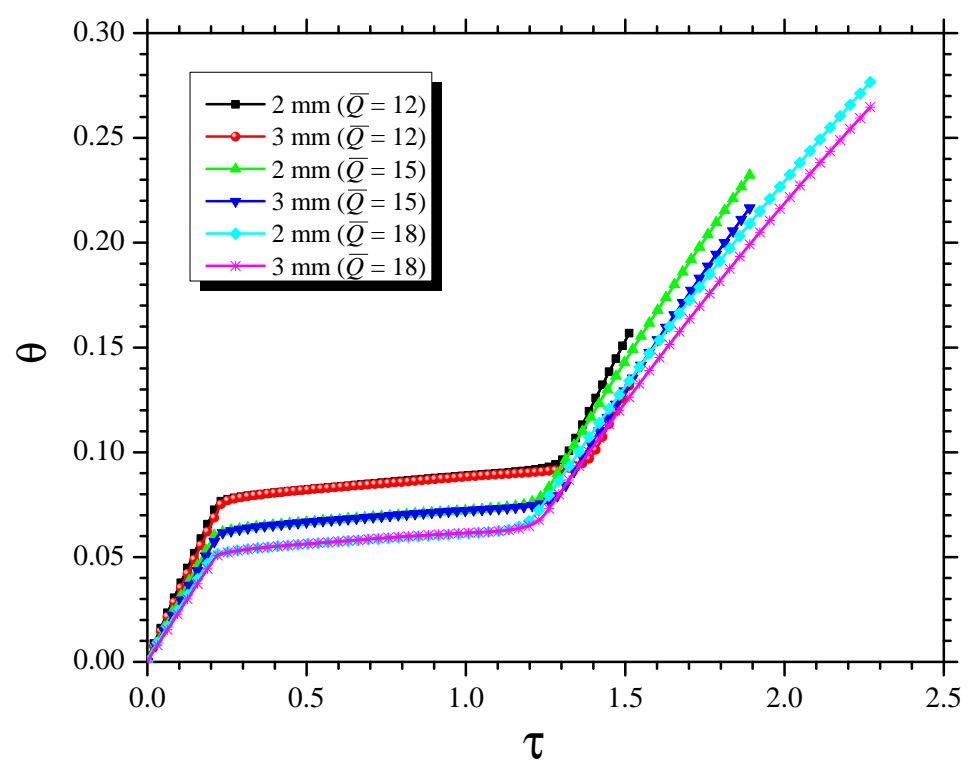

Figure 12: The variation of $\theta$ in terms of $\tau$ for different $\bar{Q}$.

fraction varies with $S t e^{*}$ similar to the $\theta$, which shows that $F o^{*}$ is further dependent on the other dimensionless parameters to generalize the liquid fraction behaviour for transient phase change heating phenomenon. Higher liquid fraction is achieved by increasing the Ste* at a constant $\mathrm{Fo}^{*}$ or a constant liquid fraction is achieved at a lower $F_{o^{*}}$ for a higher Ste which is also reported in the literature [47]. In addition, the $F o^{*}$ number is significantly reduced from 0.23 to 0.12 with the increase of $S t e^{*}$ from 0.12 to 0.21 . The reason behind such trends can be explained from Equation 24. For the constant PCM properties and PCM thickness layer, Ste* number increases by increasing $\bar{Q}$. Therefore, at constant $F o^{*}$, a higher liquid fraction is obtained by increasing $\bar{Q}$ which takes less time to complete the melting process. From Figure 13, it can been seen that $3 \mathrm{~mm}$ fin thickness finned heat sink has a higher Ste* at constant $\bar{Q}$, e.g. at $\bar{Q}=12$, Ste* is 0.12 and 0.14 for $2 \mathrm{~mm}$ and $3 \mathrm{~mm}$ fin thickness, respectively, which shows that $3 \mathrm{~mm}$ fin thickness finned heat sink has a higher capacity to absorb the heat in form of latent heat. Moreover, It can be revealed that liquid fraction is not just the function of $F o^{*}$ because the effect of phase change are not included. Thus, liquid fraction is directly a function of Ste* due to the fact that liquid fraction is changed directly with the inverse of latent heat of fusion based on the storage capacity of the PCM based finned heat sink.

Therefore, for the generalization of melting phenomenon, the results of liquid fraction are presented in Figure 14 in terms of the product of $S t e^{*}$ and $F o^{*}$ for different cases of Ste* It can be seen that the different lines of liquid fractions of are closer to each other. However, there is still a deviation in completion of melting process for a higher Ste* As reported in 
literature [47], the independent melting process is sufficiently generalized with product of $F_{o^{*}}$ Ste* . However, due to effect of natural convection in melting front (especially for high $S t e^{*}$ resulted from a high $\bar{Q}$ ), modified Rayleigh number is better to be included to propose the effect of natural convection. Figure 15 illustrate the variation of liquid fraction in terms of $F_{o^{*}} S t e^{*}$ and $R a^{*}$, namely $F o^{*} S t e^{*} R a_{t_{p}}^{*} R a_{h_{f}}^{*}$. For both fin thickness of finned heat sinks, the liquid fractions for all Ste* almost match each other, which shows a reasonable generalization of the liquid fraction in terms of the product of $F O^{*} S t e^{*} R a_{t_{p}}^{*} R a_{h_{f}}^{*}$. A curve fitting analysis is performed to develop a correlation for the liquid fraction as function of $F o^{*} S t e^{*} R a_{t_{p}}^{*} R a_{h_{f}}^{*}$ for different fin thickness of finned heat sinks:

$$
f_{l}=-50560 x^{4}+5326.8 x^{3} 124.41 x^{2}+15.74 x-0.0126 \quad\left(R^{2}=0.998\right)
$$

where, $x=F o^{*} S t e^{*} R a_{t_{p}}^{*^{0.155}} R a_{h_{f}}^{*^{-0.01}}$. Note that developed correlation is reasonable for finned heat sink chosen in current study within the parameter range: $0<F o^{*}<0.26,0.12<$ $S t e^{*}<0.21,1.54 \times 10^{3}<R a_{t_{p}}^{*^{0.155}}<4.60 \times 10^{3}, 1.71 \times 10^{7}<R a_{h_{f}^{*}}^{\text {-0.01 }^{0}}<2.56 \times 10^{7}$, $0<f_{l}<1,0<F o^{*} S t e^{*} R a_{t_{p}}^{*^{0.155}} R a_{h_{f}}^{*^{-0.01}}<0.063$. Finally, Figure 16 illustrates the $N u^{*}$

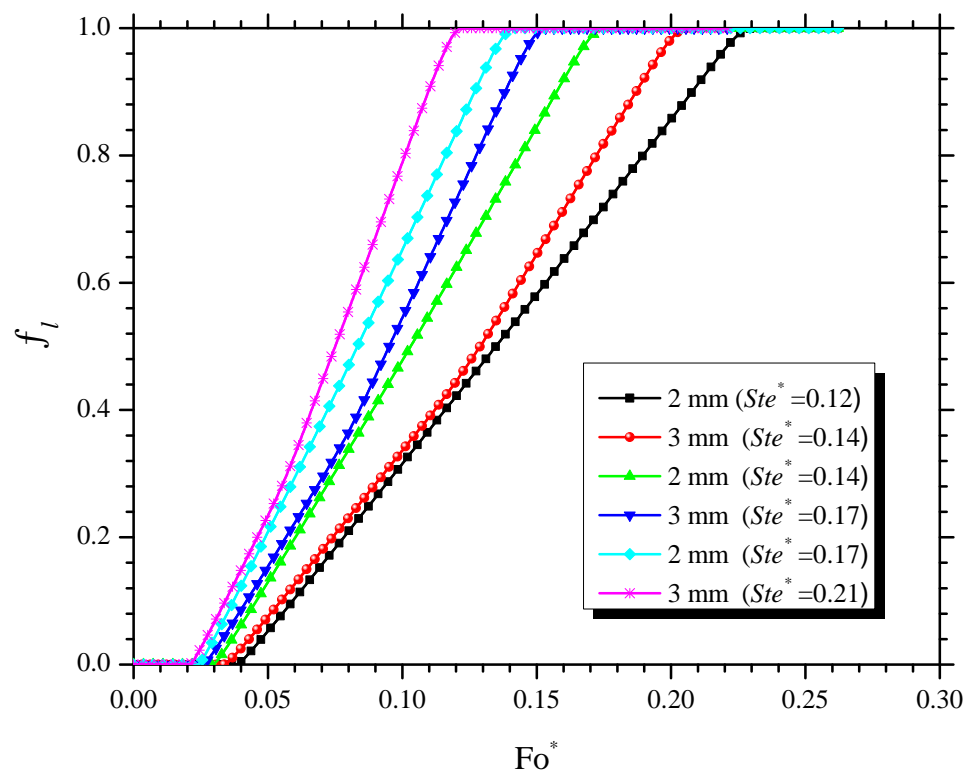

Figure 13: The variation of liquid fraction in terms of Fo* for different Ste*

variation, defined in Equation 22, with for both fin thickness at all Ste*. A similar process is performed for $N u^{*}$ to find the suitable dimensionless parameter to generalize it. The results are presented as function of dimensionless numbers $F o^{*} S t e^{*} R a_{t_{p}}^{*^{0.166}} R a_{h_{f}}^{*^{-0.25}}$ and a good agreement is achieved for both cases of finned heat sinks. The results showed that 


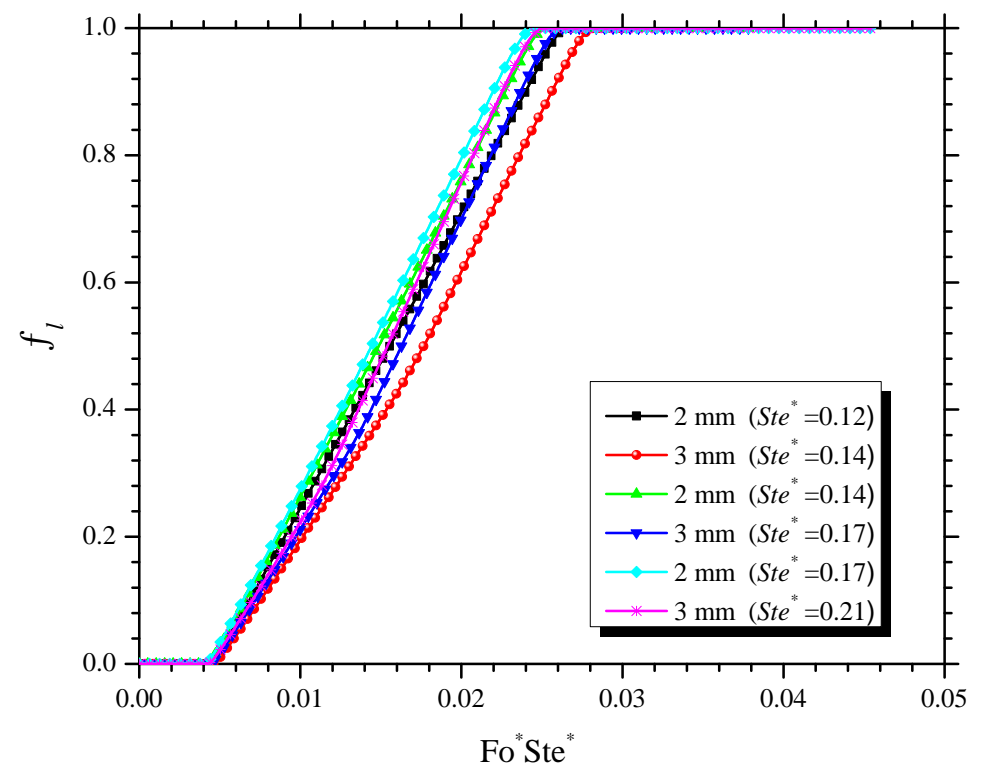

Figure 14: The variation of liquid fraction in terms of Fo*Ste* for different Ste*.

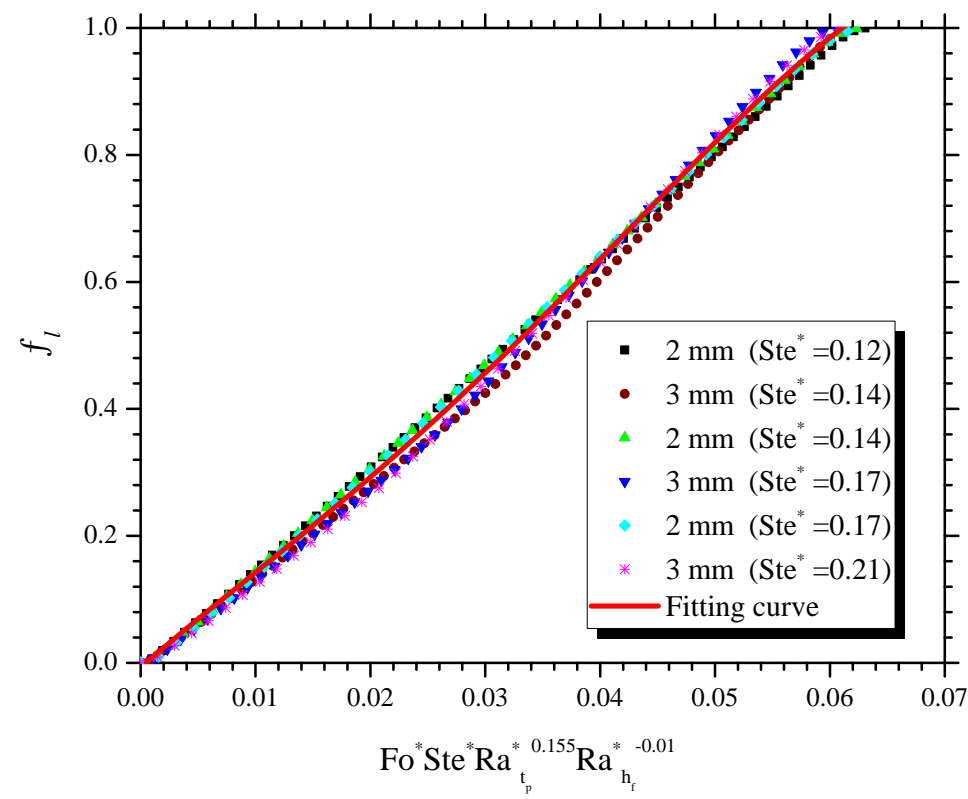

Figure 15: The variation of liquid fraction in terms of Fo*Ste* Ra* for different Ste*.

$N u^{*}$ is higher at the initial stage of melting process due to the less thermal resistance. Afterwards, $N u^{*}$ decreases sharply until the melt fraction is achieved about 0.3 and further decreases asymptotically approaching a non-zero value, which represents the heat transfer in fully melted PCM under natural convection. The following relation of $N u^{*}$ can be defined to express the results presented in Figure 16 :

$$
N u^{*}=a+\frac{b}{F O^{*} S t e^{*} R a_{t_{p}}^{* 0.166} R a_{h_{f}}^{*-0.25}+c}
$$

where constants $a=2, b=4$, and $c=0.02$ are obtained after the best fitting in current 
system. A good agreement was achieved with the Shatikian et al. [39] proposed relation of $N u^{*}$.

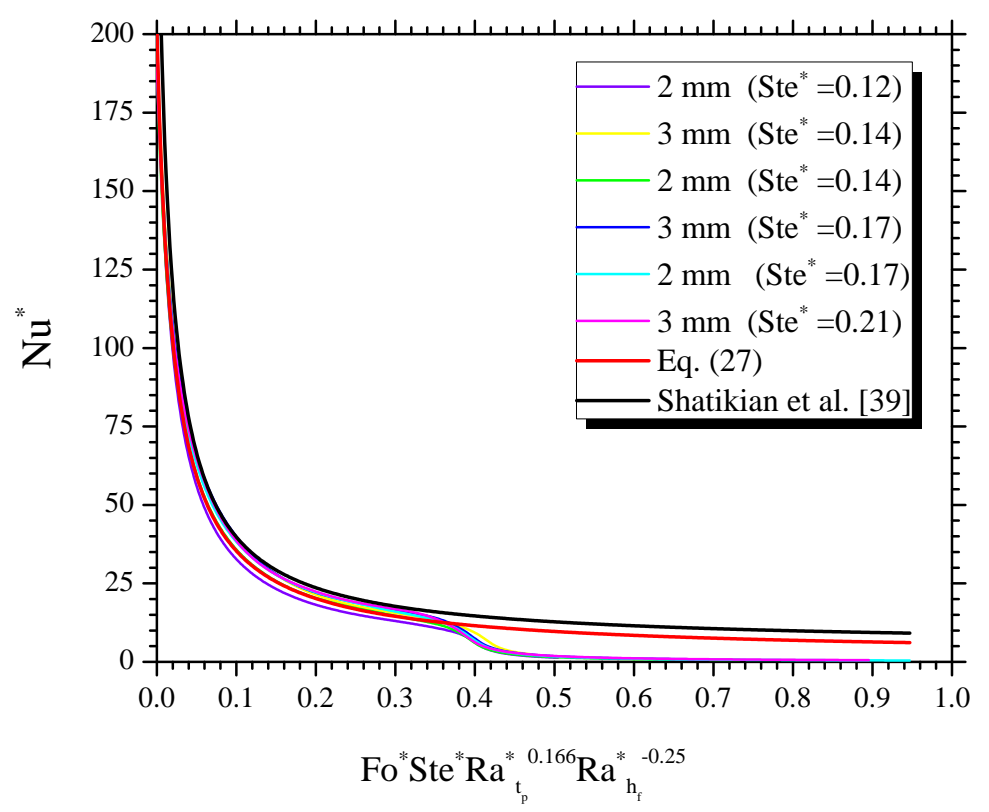

Figure 16: Distribution of $N u^{*}$ as function of $F o^{*} S t e^{*} R a_{t_{p}}^{*^{0.166}} R_{h_{f}}^{*^{-0.25}}$ and proposed correlation compared with the Shatikian et al. [39].

\section{Conclusions}

The transient $2 D$ numerical simulation of PCM filled finned heat sinks are carried out to investigate the heat transfer and flow-field characteristics having the fin thickness of 2 $\mathrm{mm}$ and $3 \mathrm{~mm}$, optimally explored from the previous experimental investigations. Three different input heating power level of 4,5 and $6 \mathrm{~W}$ are provided at base of each heat sink. The numerical results show that finned heat sink filled with PCM has the capability of uniform heat distribution inside the heat sink. Uniform melting of PCM is observed inside the fins and higher phase change duration is obtained for $3 \mathrm{~mm}$ fin thickness finned heat sink at each input heat flux. In addition, natural convection heating phenomenon is observed and velocity vectors reveal that melting of PCM occur from bottom to top of the finned heat sink. The circulating patterns are formed of vortices of the liquid PCM because of natural convection and direction of gravity. Further, the results indicated that finned heat sink of 3 mm fin thickness has the better heat transfer performance to stable the base temperature, enhances the better cooling capability and lower the maximum operating temperature as compared to $3 \mathrm{~mm}$ fin thickness finned heat sink. By increasing the power level from 4 to $6 \mathrm{~W}$, for the case of $3 \mathrm{~mm}$ fin thickness, the melting time increases by $6.63 \%, 3.59 \%$ and 
$1.90 \%$, respectively, compared to the $2 \mathrm{~mm}$ fin thickness finned heat sink. The normalized new correlations for calculation of liquid fraction and $N u^{*}$ results reveal that liquid fraction and $N u^{*}$ can be defined as a function of $F o^{*} S t e^{*} R a_{t_{p}}^{*^{0.155}} R a_{h_{f}}^{*^{-0.01}}$ and $F o^{*} S t e^{*} R a_{t_{p}}^{*^{0.166}} R a_{h_{f}}^{*^{-0.25}}$, respectively, for both $2 \mathrm{~mm}$ and $3 \mathrm{~mm}$ fin thickness finned heat sinks.

\section{Acknowledgement}

This research is facilitated by the Faculty of Engineering, University of Nottingham, UK research infrastructure. The corresponding author (Adeel Arshad) acknowledges the University of Nottingham for awarding him the Faculty of Engineering Research Excellence PhD Scholarship to pursue a Ph.D. research program.

\section{Conflict of interest}

The authors declare no conflict of interest regarding this research article. 


\section{References}

[1] S. S. Murshed, C. N. de Castro, A critical review of traditional and emerging techniques and fluids for electronics cooling, Renewable and Sustainable Energy Reviews 78 (2017) 821-833. doi:10.1016/j.rser.2017.04.112.

[2] L. Yeh, Review of heat transfer technologies in electronic equipment, Journal of electronic packaging 117 (4) (1995) 333-339.

[3] M. Eugeni, H. Elahi, F. Fune, L. Lampani, F. Mastroddi, G. P. Romano, P. Gaudenzi, Numerical and experimental investigation of piezoelectric energy harvester based on flag-flutter, Aerospace Science and Technology 97 (2020) 105634. doi:10.1016/j. ast. 2019.105634

[4] H. Elahi, M. Eugeni, P. Gaudenzi, Design and performance evaluation of a piezoelectric aeroelastic energy harvester based on the limit cycle oscillation phenomenon, Acta Astronautica 157 (2019) 233-240. doi:10.1016/j.actaastro.2018.12.044.

[5] A. Arshad, M. Jabbal, Y. Yan, Synthetic jet actuators for heat transfer enhancement a critical review, International Journal of Heat and Mass Transfer 146 (2020) 118815. doi:10.1016/j.ijheatmasstransfer.2019.118815.

[6] A. Arshad, M. Jabbal, Y. Yan, Preparation and characteristics evaluation of mono and hybrid nano-enhanced phase change materials (NePCMs) for thermal management of microelectronics, Energy Conversion and Management 205 (2020) 112444. doi: $10.1016 / j$.enconman.2019.112444.

[7] K. Nayak, S. Saha, K. Srinivasan, P. Dutta, A numerical model for heat sinks with phase change materials and thermal conductivity enhancers, International Journal of Heat and Mass Transfer 49 (11-12) (2006) 1833-1844. doi:10.1016/j.ijheatmasstransfer. 2005.10.039.

[8] V. Shatikian, G. Ziskind, R. Letan, Numerical investigation of a PCM-based heat sink with internal fins, International Journal of Heat and Mass Transfer 48 (17) (2005) 3689-3706. doi:10.1016/j.ijheatmasstransfer.2004.10.042.

[9] S. K. Saha, K. Srinivasan, P. Dutta, Studies on optimum distribution of fins in heat sinks filled with phase change materials, Journal of Heat Transfer 130 (3) (2008) 034505. doi:10.1115/1.2804948. 
[10] S. K. Saha, P. Dutta, Thermal management of electronics using PCM-based heat sink subjected to cyclic heat load, IEEE Transactions on Components, Packaging and Manufacturing Technology 2 (3) (2012) 464-473. doi:10.1109/tcpmt.2011.2180021.

[11] Y.-H. Wang, Y.-T. Yang, Three-dimensional transient cooling simulations of a portable electronic device using PCM (phase change materials) in multi-fin heat sink, Energy 36 (8) (2011) 5214-5224. doi:10.1016/j.energy.2011.06.023.

[12] Y.-T. Yang, Y.-H. Wang, Numerical simulation of three-dimensional transient cooling application on a portable electronic device using phase change material, International Journal of Thermal Sciences 51 (2012) 155-162. doi:10.1016/j.ijthermalsci.2011. 08.011 .

[13] W.-B. Ye, D.-S. Zhu, N. Wang, Numerical simulation on phase-change thermal storage/release in a plate-fin unit, Applied Thermal Engineering 31 (17-18) (2011) 38713884. doi:10.1016/j.applthermaleng.2011.07.035.

[14] R. Pakrouh, M. Hosseini, A. Ranjbar, R. Bahrampoury, A numerical method for PCMbased pin fin heat sinks optimization, Energy Conversion and Management 103 (2015) 542-552. doi:10.1016/j.enconman.2015.07.003.

[15] K. Kant, A. Shukla, A. Sharma, Performance evaluation of fatty acids as phase change material for thermal energy storage, Journal of Energy Storage 6 (2016) 153-162. doi: $10.1016 / j$.est.2016.04.002.

[16] S. K. Sahoo, P. Rath, M. K. Das, Numerical study of phase change material based orthotropic heat sink for thermal management of electronics components, International Journal of Heat and Mass Transfer 103 (2016) 855-867. doi:10.1016/j. ijheatmasstransfer.2016.07.063.

[17] J. Vogel, J. Felbinger, M. Johnson, Natural convection in high temperature flat plate latent heat thermal energy storage systems, Applied Energy 184 (2016) 184-196. doi: $10.1016 / \mathrm{j}$. apenergy.2016.10.001.

[18] V. Joshi, M. K. Rathod, Constructal enhancement of thermal transport in latent heat storage systems assisted with fins, International Journal of Thermal Sciences 145 (2019) 105984. doi:10.1016/j.ijthermalsci.2019.105984. 
[19] C. Ji, Z. Qin, Z. Low, S. Dubey, F. H. Choo, F. Duan, Non-uniform heat transfer suppression to enhance PCM melting by angled fins, Applied Thermal Engineering 129 (2018) 269-279. doi:10.1016/j.applthermaleng.2017.10.030.

[20] M. Kazemi, M. Hosseini, A. Ranjbar, R. Bahrampoury, Improvement of longitudinal fins configuration in latent heat storage systems, Renewable Energy 116 (2018) 447-457. doi:10.1016/j.renene.2017.10.006.

[21] R. Kalbasi, M. Afrand, J. Alsarraf, M.-D. Tran, Studies on optimum fins number in PCM-based heat sinks, Energy 171 (2019) 1088-1099. doi:10.1016/j.energy.2019. 01.070 .

[22] A. Arshad, H. M. Ali, M. Ali, S. Manzoor, Thermal performance of phase change material (PCM) based pin-finned heat sinks for electronics devices: Effect of pin thickness and PCM volume fraction, Applied Thermal Engineering 112 (2017) 143-155. doi:10.1016/j.applthermaleng.2016.10.090.

[23] A. Arshad, H. M. Ali, W.-M. Yan, A. K. Hussein, M. Ahmadlouydarab, An experimental study of enhanced heat sinks for thermal management using n-eicosane as phase change material, Applied Thermal Engineering 132 (2018) 52-66. doi: 10.1016/j.applthermaleng.2017.12.066.

[24] A. Arshad, H. M. Ali, S. Khushnood, M. Jabbal, Experimental investigation of PCM based round pin-fin heat sinks for thermal management of electronics: Effect of pinfin diameter, International Journal of Heat and Mass Transfer 117 (2018) 861-872. doi:10.1016/j.ijheatmasstransfer.2017.10.008.

[25] H. M. Ali, A. Arshad, Experimental investigation of n-eicosane based circular pin-fin heat sinks for passive cooling of electronic devices, International Journal of Heat and Mass Transfer 112 (2017) 649-661. doi:10.1016/j.ijheatmasstransfer.2017.05. 004.

[26] H. M. Ali, A. Arshad, M. Jabbal, P. Verdin, Thermal management of electronics devices with PCMs filled pin-fin heat sinks: A comparison, International Journal of Heat and Mass Transfer 117 (2018) 1199-1204. doi:10.1016/j.ijheatmasstransfer.2017.10. 065. 
[27] H. M. Ali, A. Arshad, M. M. Janjua, W. Baig, U. Sajjad, Thermal performance of LHSU for electronics under steady and transient operations modes, International Journal of Heat and Mass Transfer 127 (2018) 1223-1232. doi:10.1016/j.ijheatmasstransfer. 2018.06.120.

[28] M. J. Ashraf, H. M. Ali, H. Usman, A. Arshad, Experimental passive electronics cooling: Parametric investigation of pin-fin geometries and efficient phase change materials, International Journal of Heat and Mass Transfer 115 (2017) 251-263. doi:10.1016/ j.ijheatmasstransfer.2017.07.114.

[29] H. M. Ali, M. J. Ashraf, A. Giovannelli, M. Irfan, T. B. Irshad, H. M. Hamid, F. Hassan, A. Arshad, Thermal management of electronics: An experimental analysis of triangular, rectangular and circular pin-fin heat sinks for various PCMs, International Journal of Heat and Mass Transfer 123 (2018) 272-284. doi:10.1016/j.ijheatmasstransfer. 2018.02 .044

[30] H. Usman, H. M. Ali, A. Arshad, M. J. Ashraf, S. Khushnood, M. M. Janjua, S. N. Kazi, An experimental study of PCM based finned and un-finned heat sinks for passive cooling of electronics, Heat and Mass Transfer 54 (12) (2018) 3587-3598. doi:10. $1007 / \mathrm{s} 00231-018-2389-0$.

[31] R. Baby, C. Balaji, Experimental investigations on phase change material based finned heat sinks for electronic equipment cooling, International Journal of Heat and Mass Transfer 55 (5-6) (2012) 1642-1649. doi:10.1016/j.ijheatmasstransfer.2011.11. 020.

[32] S. Saha, P. Dutta, Heat transfer correlations for PCM-based heat sinks with plate fins, Applied Thermal Engineering 30 (16) (2010) 2485-2491. doi:10.1016/j. applthermaleng.2010.06.021.

[33] M. A. Bashir, A. Giovannelli, Design optimization of the phase change material integrated solar receiver: A numerical parametric study, Applied Thermal Engineering 160 (2019) 114008. doi:10.1016/j.applthermaleng.2019.114008.

[34] A. Shahsavar, A. Shaham, P. Talebizadehsardari, Wavy channels triple-tube LHS unit with sinusoidal variable wavelength in charging/discharging mechanism, International 
Communications in Heat and Mass Transfer 107 (2019) 93-105. doi:10.1016/j. icheatmasstransfer.2019.05.012.

[35] J. M. Mahdi, E. C. Nsofor, Melting enhancement in triplex-tube latent heat energy storage system using nanoparticles-metal foam combination, Applied Energy 191 (2017) 22-34. doi:10.1016/j.apenergy.2016.11.036.

[36] J. M. Mahdi, E. C. Nsofor, Melting enhancement in triplex-tube latent thermal energy storage system using nanoparticles-fins combination, International Journal of Heat and Mass Transfer 109 (2017) 417-427. doi:10.1016/j.ijheatmasstransfer.2017.02. 016.

[37] W. R. Humphries, E. I. Griggs, A design handbook for phase change thermal control and energy storage devices, NASA STI/recon technical report N 78.

[38] A. D. Brent, V. R. Voller, K. J. Reid, Enthalpy-porosity technique for modeling convection-diffusion phase change: application to the melting of a pure metal, Numerical Heat Transfer 13 (3) (1988) 297-318. doi:10.1080/10407788808913615.

[39] V. Shatikian, G. Ziskind, R. Letan, Numerical investigation of a PCM-based heat sink with internal fins: Constant heat flux, International Journal of Heat and Mass Transfer 51 (5-6) (2008) 1488-1493. doi:10.1016/j.ijheatmasstransfer.2007.11.036.

[40] S. Fok, W. Shen, F. Tan, Cooling of portable hand-held electronic devices using phase change materials in finned heat sinks, International Journal of Thermal Sciences 49 (1) (2010) 109-117. doi:10.1016/j.ijthermalsci.2009.06.011.

[41] S. Hosseinizadeh, F. Tan, S. Moosania, Experimental and numerical studies on performance of PCM-based heat sink with different configurations of internal fins, Applied Thermal Engineering 31 (17-18) (2011) 3827-3838. doi:10.1016/j .applthermaleng. 2011.07 .031 .

[42] S. Patankar, Numerical heat transfer and fluid flow, Hemisphere Publishing Corporation; McGraw-Hill Book Company, New York., 2018.

[43] A. Shahsavar, A. A. Al-Rashed, S. Entezari, P. T. Sardari, Melting and solidification characteristics of a double-pipe latent heat storage system with sinusoidal 
wavy channels embedded in a porous medium, Energy 171 (2019) 751-769. doi: $10.1016 / j$. energy.2019.01.045.

[44] S. Song, Q. Liao, W. Shen, Y. Ruan, J. Xu, Numerical study on laminar convective heat transfer enhancement of microencapsulated phase change material slurry using liquid metal with low melting point as carrying fluid, International Journal of Heat and Mass Transfer 62 (2013) 286-294. doi:10.1016/j.ijheatmasstransfer.2013.03.013.

[45] R. Srikanth, C. Balaji, Experimental investigation on the heat transfer performance of a PCM based pin fin heat sink with discrete heating, International Journal of Thermal Sciences 111 (2017) 188-203. doi:10.1016/j.ijthermalsci.2016.08.018.

[46] S. Mat, A. A. Al-Abidi, K. Sopian, M. Sulaiman, A. T. Mohammad, Enhance heat transfer for PCM melting in triplex tube with internal-external fins, Energy Conversion and Management 74 (2013) 223-236. doi:10.1016/j.enconman.2013.05.003.

[47] Y. Xu, M.-J. Li, Z.-J. Zheng, X.-D. Xue, Melting performance enhancement of phase change material by a limited amount of metal foam: Configurational optimization and economic assessment, Applied Energy 212 (2018) 868-880. doi:10.1016/j.apenergy. 2017.12 .082 